OPEN ACCESS

Edited by:

Flavio Almeida Amaral, Federal University of Minas Gerais,

Brazil

Reviewed by: Akiko Takahashi, Japanese Foundation For Cancer

Research, Japan Pedro Elias Marques, KU Leuven, Belgium

*Correspondence: Nicolas Riteau nicolas.riteau@cnrs-orleans.fr

Specialty section: This article was submitted to Inflammation,

a section of the journal

Frontiers in Immunology

Received: 05 August 2021 Accepted: 03 September 2021

Published: 01 October 2021

Citation:

Couillin I and Riteau N (2021) STING Signaling and Sterile Inflammation.

Front. Immunol. 12:753789. doi: 10.3389/fimmu.2021.753789

\section{STING Signaling and Sterile Inflammation}

\author{
Isabelle Couillin and Nicolas Riteau* \\ Experimental and Molecular Immunology and Neurogenetics Laboratory (INEM), Centre National de la Recherche Scientifique \\ (CNRS), UMR7355 and University of Orleans, Orleans, France
}

Innate immunity is regulated by a broad set of evolutionary conserved receptors to finely probe the local environment and maintain host integrity. Besides pathogen recognition through conserved motifs, several of these receptors also sense aberrant or misplaced self-molecules as a sign of perturbed homeostasis. Among them, self-nucleic acid sensing by the cyclic GMP-AMP synthase (cGAS)/stimulator of interferon genes (STING) pathway alerts on the presence of both exogenous and endogenous DNA in the cytoplasm. We review recent literature demonstrating that self-nucleic acid detection through the STING pathway is central to numerous processes, from cell physiology to sterile injury, autoimmunity and cancer. We address the role of STING in autoimmune diseases linked to dysfunctional DNAse or related to mutations in DNA sensing pathways. We expose the role of the cGAS/STING pathway in inflammatory diseases, neurodegenerative conditions and cancer. Connections between STING in various cell processes including autophagy and cell death are developed. Finally, we review proposed mechanisms to explain the sources of cytoplasmic DNA.

Keywords: STING, cGAS, self-DNA, sterile inflammation, autophagy, type I IFN 


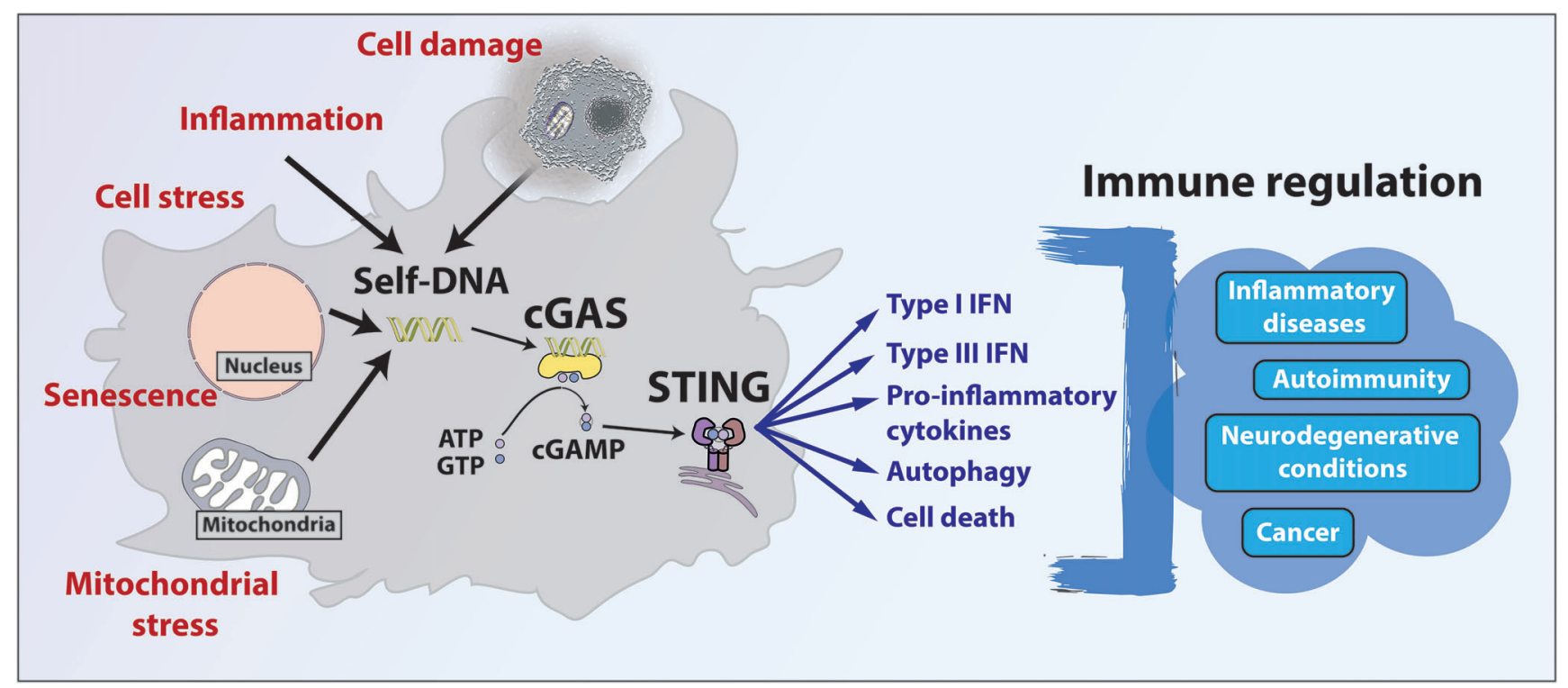

GRAPHICAL ABSTRACT | Illustration of the diversity of processes triggering self-DNA mediated CGAS/STING activation and subsequent pathways involved in the immune regulation of various conditions.

\section{INTRODUCTION}

Supported by Charles Janeway's central model of innate immunity based on pathogen recognition through conserved motifs (1), host detection of pathogen-derived nucleic acids by pathogen recognition receptors (PRRs) is a common and effective strategy to sense invading microorganisms and initiate innate and adaptive immune responses (2). PRRs are also involved in context-dependent recognition of self-nucleic acids, either nuclear DNA (nDNA) or mitochondrial DNA (mtDNA) (3-6). This is in line with Polly Matzinger's model proposing that in numerous instances what ultimately matters for a host is to detect danger independently of its external or internal origin to mount an immune response. Cell stress or damage results in the production and/or the release of host-derived danger signals (7). Apart from mitosis, cell DNA is confined within the nucleus or mitochondria. DNA in the cytoplasm, from microbial origin (e.g. following viral or bacterial infection) or from the host own genetic material, informs of a potentially deleterious situation and the latter constitutes an endogenous danger signal.

Among PRRs involved in self-nucleic acid recognition, an increasing interest has emerged for STimulator of Interferon Genes (STING), also known as TMEM173, MPYS or MITA (6, 8-10). STING is an endoplasmic reticulum (ER)-located PRR, which does not directly bind to DNA. Its activating ligands are cyclic dinucleotides (CDNs). CDNs are produced as second messengers by microorganisms $(11,12)$ or synthesized by the enzyme cyclic GMP-AMP synthase (cGAS) in response to binding either host- or pathogen-derived cytosolic doublestranded (ds)DNA $(6,13-15)$. While displaying no apparent DNA sequence specificity (16), cGAS activity is limited by spatial distribution of its substrate as well as its degradation by host
DNases. cGAS binds to nDNA (17) or mtDNA (18) that can be continuous, fragmented or supercoiled (17). Crystal structure analysis of mouse cGAS revealed that it functions as a dimer, with each protein catalytic domain binding to an 18 base pairs (bp) double-stranded (ds) DNA at two different sites, forming a $2: 2$ complex $(19,20)$. While initially described as a cytoplasmic protein, a recent study found that cGAS binds to the inner leaflet of the plasma membrane to regulate its activity and prevent overactivation from genotoxic stress (21). Other studies proposed that cGAS resides predominantly in the nucleus of various mouse and human cell lines, as well as human peripheral blood mononuclear cells (PBMC)-derived macrophages and dendritic cells $(22,23)$. However, its baseline activation in the nucleus is prevented by poorly accessible nucleosomal state of nDNA $(20,22,24)$. Thus, cGAS cellular localization appears unclear and additional studies are required.

DNA binding to cGAS triggers ATP and GTP conversion into cyclic guanosine monophosphate-adenosine monophosphate (cGAMP). cGAMP is the canonical CDN that binds and activates STING (Figure 1). cGAMP binding to STING elicits a conformational shift and its dimerization as well as its translocation to the ER-Golgi intermediate compartment (ERGIC). STING dimers recruit TANK-binding kinase 1 (TBK1), which phosphorylates STING on Ser366 to serve as a docking site for interferon regulatory factor 3 (IRF3) and its phosphorylation by TBK1. STING also leads to nuclear factor $\kappa B$ (NF- $\kappa B$ ) activation. IRF3 and NF- $\mathrm{BB}$ transcription factors induce the production of type I interferons (IFNs) and other cytokines involved in host immune responses $(6,8,25,26)$. Interestingly, recent studies showed that STING stimulation can also lead to type III IFN production (also known as IL-28/IL-29 or IFN- $\lambda)(27-29)$. Besides its roles in the regulation of gene 


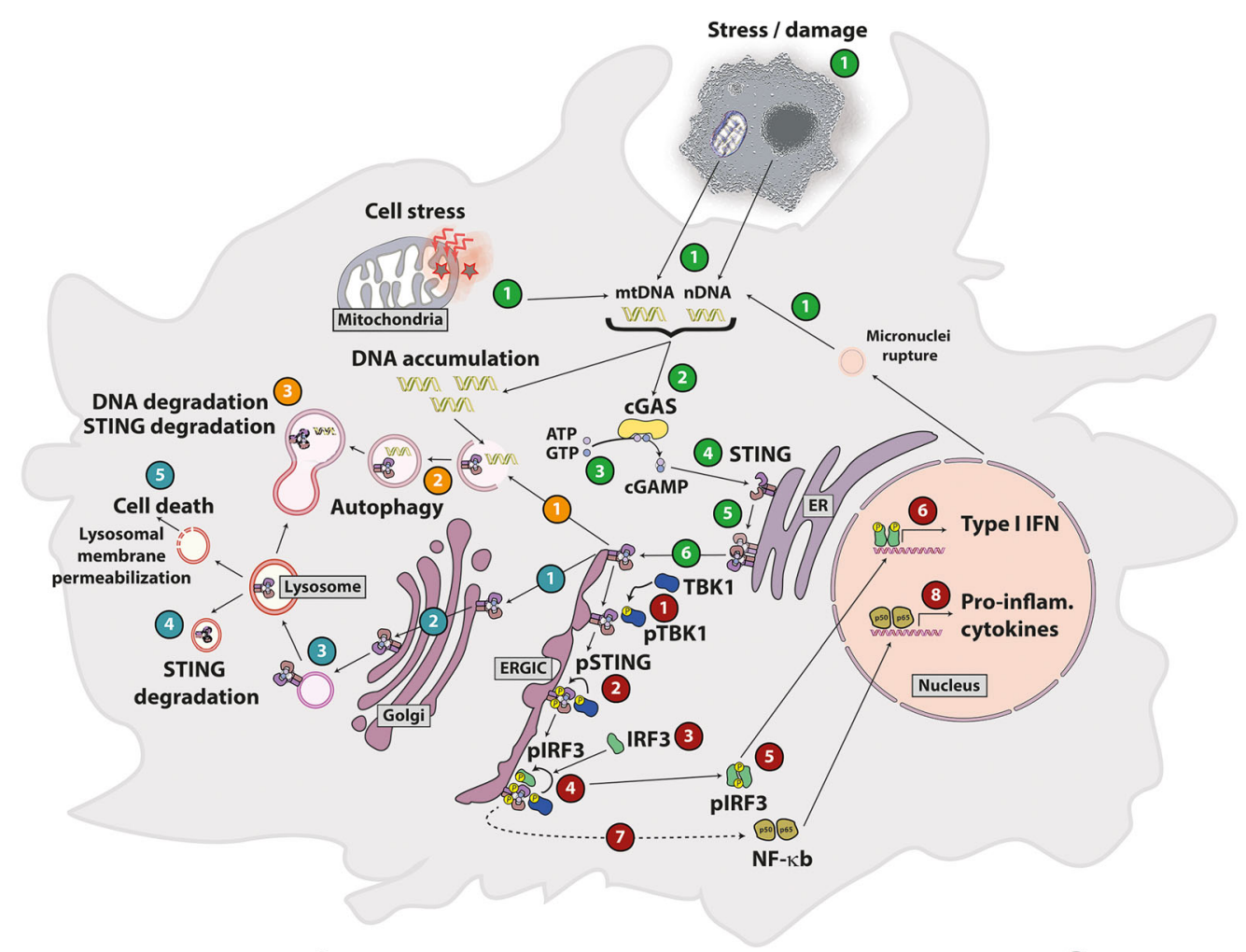

Numerous situations lead to the (1) presence of nuclear DNA (nDNA) and mitochondrial DNA ( $\mathrm{mtDNA}$ ) in the cytoplasm where (2) they bind to cGAS DNA binding to cGAS induces (3) the production of the cyclic dinucleotide 2', 3'-cyclic GMP-AMP (2',3'-cGAMP) from ATP and GTP. (4) cGAMP binds to STING located in the endoplasmic reticulum (ER) membrane, which undergoes (5) a conformational shift and dimerizes. Active STING (6) translocates from the ER to the ER-Golgi intermediate compartment (ERGIC). STING 1 recruits TANK-binding kinase 1 (TBK1) which autophosphorylates (pTBK1). In turn, PTBK1 2 phosphorylates STING, which is used as a 3 docking site for interferon regulatory factor 3 (IRF3). TBK1 4 phosphorylates IRF3, which (5) functions as dimeric transcription factor to (6) activate genes encoding for type I interferons (IFN). Active STING also induces 7 NF-KB activation leading to the 8 transcription of pro-inflammatory genes. Alternatively, STING-containing ERGIC serves (1) as a membrane source for (2) autophagosome formation in an LC3-dependent manner and (3) fuses with lysosomes allowing STING degradation and recycling of accumulated DNA. STING protein also (1) enters the Golgi apparatus and (2) traffic through the cisternae and to (3) late endosome and lysosome. Lysosomal STING (4) is degraded and (5) leads to membrane permeabilization and lysosomal cell death.

FIGURE 1 | Self-DNA-mediated activation of the CGAS/STING pathway.

expression, STING induces non-canonical autophagy through its direct interaction with the microtubule-associated protein light chain 3 (LC3), a key initiator of autophagy that cycles between the nucleus and cytoplasm $(25,30-32)$. Importantly, STINGinduced autophagy mediates the clearance of cytosolic DNA (30). STING also regulates various cell death processes including lysosomal cell death (33), apoptosis (34) and necroptosis (35). Of note, in addition to cGAS, other cytosolic receptors (e.g. DDX41, IFI16) can sense DNA or CDNs and activate STING $(36,37)$. The cGAS/STING pathway is important to control viral and bacterial pathogen infection $(38,39)$ as well as for immune surveillance $(40$, 41). STING is ubiquitously expressed in a variety of tissues including lungs, liver, kidney, heart and spleen (8). STING is expressed in both innate and adaptive immune cells (e.g. macrophages (8), dendritic cells (8), natural killer cells (42), CD4 ${ }^{+}$ and $\mathrm{CD} 8^{+} \mathrm{T}$ lymphocytes (43) and B lymphocytes (44). It is also expressed by nonhematopoietic-derived cells including endothelial cells (45), epithelial cells (46) and neurons (47).
Here, we detailed known mechanisms to explain DNA access to the cytoplasm, briefly review STING allelic variants and then focus on STING biology in the context of self-DNA sensing associated with autoimmunity, cancer or sterile inflammatory settings.

\section{DNA ACCESS TO CYTOPLASM}

Host DNA, which resides within the nucleus or mitochondria, may be released into the cytoplasm following numerous processes, including genomic DNA instability, mitochondrial stress and endosomal/lysosomal rupture (Figure 2). For instance, nDNA-containing micronuclei rupture $(17,48)$ and mitochondrial stress (49-52) lead to DNA release in the cytoplasm and cGAS activation. MtDNA stress elicited by mitochondrial transcription factor A (TFAM) deficiency induces its release into the cytosol and activates the cGAS/ 


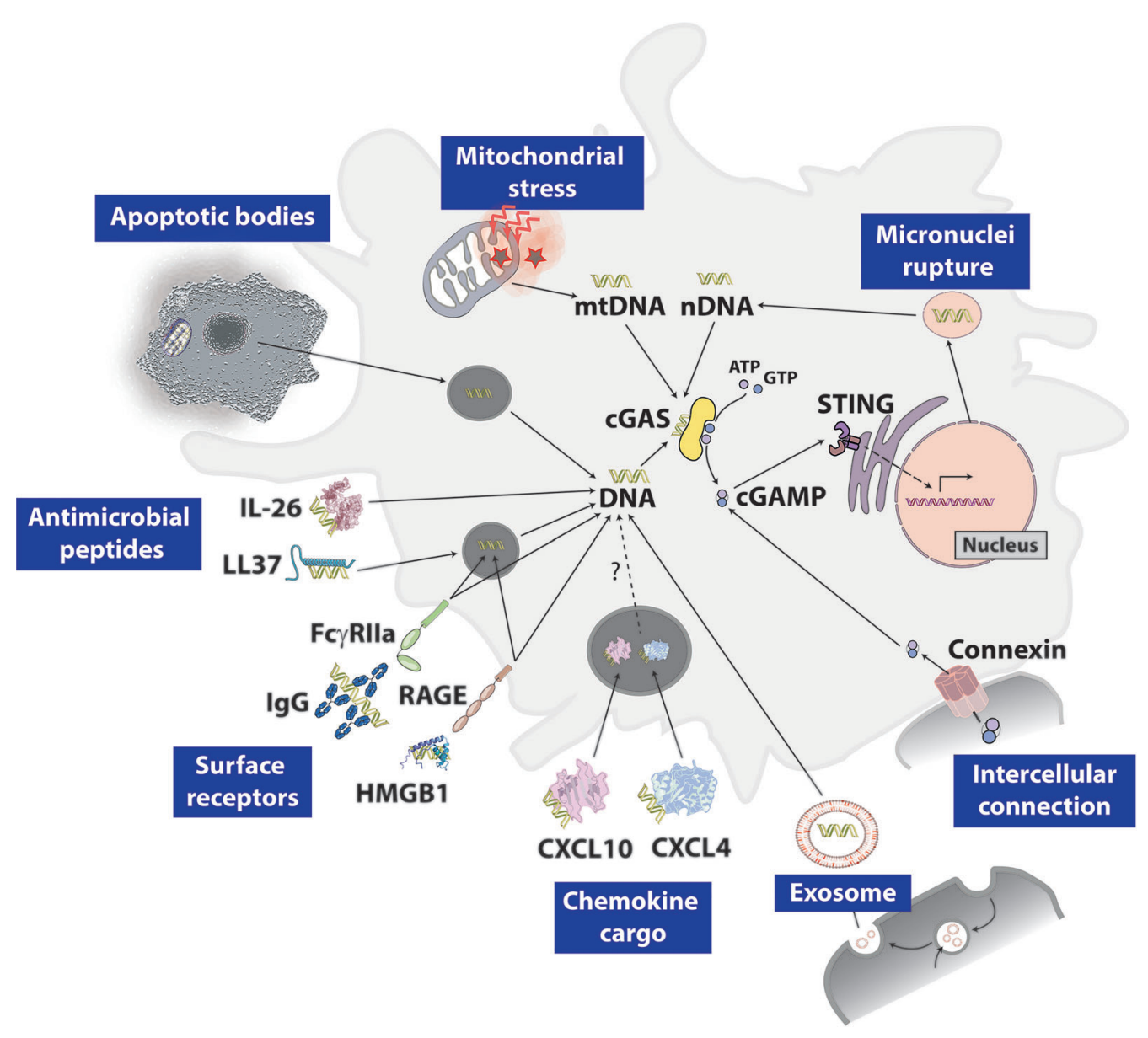

FIGURE 2 | Proposed mechanism for self-DNA access to the cytoplasm. Mitochondrial stress-induced membrane permeability with mitochondrial DNA (mtDNA) leakage and chromosomal instability/senescence lead to micronucleus formation from incomplete segregation of chromatin and micronucleus rupture induces cytosolic nuclear DNA (nDNA). Multiples pathways lead to self-DNA internalization within endosomal structures and we believe that endosomal pathway perturbation leads to cytosolic delivery of DNA and CGAS/STING pathway activation. Apoptotic bodies engulfment may enable self-DNA delivery in the cytoplasm. The antimicrobial peptide LL37 and IL-26 bind to genomic DNA and induce its translocation within endosomes and/or in the cytoplasm. CXCL4- and CXCL10-DNA complexes as well as cell surface receptors FcyRlla or receptor for advanced glycation end products (RAGE) bind to IgG- or HMGB1-bound DNA, respectively, and may lead to cGAS activation upon cytosolic DNA release. DNA-containing exosomes constitute another source of cGAS activation. Finally, cGAMP enters the cell from neighboring ones through gap junctions to directly activate STING.

STING pathway leading to type I IFN-dependent interferon stimulated genes (ISGs) expression and increased antiviral capacity (26). DsDNA from dying cells stimulates STING pathway in surrounding cells, suggesting that extrinsic phagocytic DNA improperly processed within lysosomes access the cytosol $(53,54)$. The mechanisms by which self-DNA from neighboring cells becomes accessible for intracellular DNA sensors remain uncertain. Several context-dependent pathways have been reported, such as IgG- or HMGB1-bound DNA internalization following interaction with FcyRIIa or receptor for advanced glycation end products (RAGE), respectively (55). The antimicrobial peptide LL37 was shown to transport extracellular DNA into the cytoplasm of human primary monocytes triggering STING activation (56). IL-10-family member IL-26 binds to genomic, mtDNA or neutrophil extracellular traps (NETS) DNA and traffic them into the cytosol of human myeloid cells activating STING (57). Radiotherapy-induced cytosolic dsDNA accumulation in cancer cells activates the cGAS/STING pathway to promote type I IFN production-dependent protective effect, notably by recruiting BATF3-dependent DCs (58). It was shown that exosomes-containing DNA from cancer cells can be transferred to the cytoplasm of DCs (58).

Besides chemotactic properties following their binding to chemokine receptors (CXCR), several chemokines display other functions. In particular, CXCL4 and CXCL10 have been shown to activate endosomal TLR9. CXCL4 binds to self and foreign DNA to form liquid crystalline complexes amplifying TLR9-mediated IFN- $\alpha$ production in systemic sclerosis (59). Neutrophil-derived CXCL10 binds to commensal skin 
microbiota DNA and triggers TLR9/type I IFN-dependent innate repair responses in injured skin (60). It remains to be determined whether CXCL4- or CXCL10-DNA complexes can activate intracellular sensors such as cGAS.

cGAMP transfer from producing cells to neighboring ones through gap junctions promotes STING activation and antiviral immunity independently of type I IFN signaling (61). cGASderived cGAMP in tumor cells diffuses to neighboring noncancerous cells through gap-junction channels to activate STING, contributing to the recruitment of protective tumorinfiltrating immune cells such as NK cells (62).

\section{STING ALLELIC VARIANTS}

There are several STING allelic variants in the general population (63). The most commons are $\mathrm{R} 232 \mathrm{H}$ and $\mathrm{R} 71 \mathrm{H}$ G230A-R293Q (HAQ). Their prevalence varies among ethnic populations. On average, about $15 \%$ and $20 \%$ of worldwide population carries at least one copy of $232 \mathrm{H}$ or HAQ variants, respectively (63-65). Alterations in STING biology induced by these point mutations are not fully clear and apparent discrepancies have been reported. Using ectopic overexpression systems, human HAQ variant exhibited a decreased response to exogenous CDNs (63) while its response to 2'3'cGAMP was either normal (63) or absent (64). STING $\mathrm{R} 232 \mathrm{H}$ showed reduced responsiveness to most exogenous CDNs although its response to 2'3'cGAMP was relatively normal $(63,64)$ or reduced $(66)$. Interestingly, it was shown that R293Q STING variant displays protective effects against obesity-associated cardiovascular disease (67) and tobaccoinduced aging-associated diseases (68). In contrast, gain-offunction point mutations in the gene encoding STING (e.g. V155M) are responsible for STING-associated vasculopathy with onset in infancy (SAVI), a rare inflammatory and autoimmune condition $(69,70)$.

\section{STING AND AUTOIMMUNE OR AUTOINFLAMMATORY DISEASES}

\section{STING-Associated Vasculopathy With Onset in Infancy}

In 2014, it was discovered that point gain-of-function mutations in TMEM173 (i.e. N154S, V155M, and V147L) from six unrelated children cause SAVI (69). SAVI is an autoinflammatory disease with early-onset systemic inflammation, cutaneous vasculopathy and interstitial lung disease $(69,71)$. Children PBMCs display constitutive STING activation, leading to higher transcription baseline for IFNB1, IL6 and TNF as well as ISGs such as CXCL10 as compared to PBMCs from healthy controls. In contrast, baseline and cGAMP-induced transcription levels of IFNA4, IFNG and IL1B were similar between patients and controls (69). The same year, V155M point mutation in STING was also found in patients with familial lupus-like phenotypes (70). STING mutant spontaneously localizes in the Golgi of patient fibroblasts and is constitutively active in the absence of exogenous 2 '3'-cGAMP in vitro (70).

Two STING knock-in mouse strains corresponding to mutations found in SAVI patients have been generated. Heterozygous V154M STING (equivalent to V155M in patients) and heterozygous STING N153S (equivalent to N154S in patients) mouse strains both display severe combined immunodeficiency disease (SCID) phenotype and thymocytes impairment at early stages (72-74). Interestingly, STING N153Sassociated lung disease is T lymphocyte-dependent but does not require IRF3/IRF7 nor type I IFN signaling (75). STINGassociated vasculopathy also develops independently of IRF3 in mice (73).

\section{Bloom Syndrome}

Bloom syndrome is a rare autosomal recessive genetic disorder caused by mutations in the BLM gene encoding BLM RecQ-like helicase (76), which maintains DNA stability during cell replication. BLM protein deficiency or lack of protein activity leads to increased mutations. Bloom syndrome is characterized by short stature, cancer predisposition, genomic instability and accumulation of micronuclei. A recent study showed that BLMdeficient fibroblasts display constitutive ISGs up-regulation in a cGAS/STING/IRF3-dependent mechanism (77). Further investigation are required to determine the exact contribution of the STING pathway in Bloom syndrome.

\section{Multiple Sclerosis}

Multiple sclerosis (MS) is a demyelinating condition that can affect both the brain and spinal cord. It was shown that STING activation attenuates experimental autoimmune encephalitis (EAE) utilized as an MS model by attenuating effector $\mathrm{T}$ cell infiltration and inducing a dominant $\mathrm{T}$ regulatory (Treg) response (78). Systemic treatments with DNA nanoparticles or CDNs activate the STING/type I IFN pathway enhancing indoleamine 2,3 dioxygenase (IDO) enzyme activity in dendritic cells promoting Treg cells (78). Another study showed that FDA-approved antiviral drug ganciclovir (GCV) induces a STING-dependent type I IFN response inhibiting inflammation in cultured myeloid cells and in EAE model (79). Together, STING pathway appears to be an important regulator of microglial reactivity and neuroinflammation with possible beneficial therapeutic effects for MS patients.

\section{Type I Diabetes}

Type 1 diabetes (T1D), sometimes referred to as juvenile diabetes, is caused by the destruction of pancreatic beta cells resulting in insufficient amount of insulin and hence elevated blood sugar levels. High glucose environment increases ROS production, triggering mitochondrial stress and mtDNA release in retinal cells and activating the cGAS/STING pathway leading to IRF3 activation via ERK1/2-Akt-tuberin - mechanistic target of rapamycin (mTOR) dependent pathways (49). Treatments with DNA nanoparticles or cGAMP attenuate type I diabetes progression in non-obese diabetic (NOD) female mice by inducing type I IFN-dependent IDO activity which promotes Treg cell function and therefore limits autoimmunity (80). It was 
further shown that TBK1 in monocytes from type 1 diabetes patients is important for IFN- $\alpha$ production in response to $\mathrm{CpG}$ DNA stimulation (81).

\section{Dysfunctional DNase and Autoimmune Diseases}

An expected consequence of self-DNA-triggered immunity is tolerance breakdown and autoimmunity $(82,83)$. Host cytoplasmic DNA sensing is typically prevented since it is usually restricted to the nucleus and mitochondria. However, multiple situations lead to the presence of misplaced DNA and autoimmunity can result from failure to properly dispose it through DNAse activity. Besides cell extrinsic DNAse I, mammalian cells express the endonuclease DNase II and the exonuclease TREX1/DNase III located within lysosomes and in the cytosol in an ER tail-anchored manner, respectively. In human, loss-of-function mutations in TREX1 trigger autoimmune diseases, such as Aicardi-Goutières syndrome (AGS), systemic lupus erythematosus (SLE), familial chilblain lupus (FCL), and retinal vasculopathy with cerebral leukodystrophy (RVCL) $(84,85)$. Recent data suggest that STING pathway may be involved in these autoimmune diseases linked to dysregulated nucleases activity (84).

\section{Aicardi-Goutières Syndrome}

Aicardi-Goutières syndrome (AGS) is a neuroinflammatory autoimmune disease triggered by mutations in genes encoding nucleotide-processing proteins. Trex1-deficient mice succumb from systemic inflammation during early adulthood $(86,87)$ whereas DNase II-deficient mice are embryonic lethal (88). Interestingly, lethality observed in both Trex1 or Dnase IIdeficient mice is rescued by crossing these mice to either $c G a s$ or Sting-deficient mice $(54,89)$. It was shown that STING-mediated type I IFN production in Trex1-deficient mice occurs first in nonhematopoietic cells, which trigger $\mathrm{T}$ and $\mathrm{B}$ lymphocytesmediated inflammation and autoantibody production (90).

RNase $\mathrm{H} 2$ is essential to remove ribonucleotides incorporated in genomic DNA during replication. Defective RNase $\mathrm{H} 2$ leads to AGS by promoting self-nucleic acid accumulation leading to chronic type I IFN production. A knock-in mouse strain containing an RNase H2 AGS mutation (G37S) shows perinatal lethality. This phenotype is partially rescued when these mice are crossed with Sting-deficient mice (91), confirming that STING signaling pathway is involved in AGS. Using in vitro RnaseH2a G37S/G37S mouse embryonic fibroblast (MEF) cell cultures, the authors confirmed that the cGAS/STING pathway triggers type I IFN and ISGs upregulation (91). The exact mechanism by which defective RNase H2 leads to cGAS activation remains to be determined.

\section{Systemic Lupus Erythematosus}

Systemic lupus erythematosus (SLE) development is classically linked to endosomal toll like receptor (TLR) 7 and TLR9 nucleic acid sensors engagement and the role of the cGAS/STING pathway remains elusive. PBMCs from SLE patients express high levels of cGAS (92). It was recently shown that in contrast to healthy donors, most monocytes from lupus patients produce IFN- $\alpha$ following 2' 3 'cGAMP stimulation and the frequency of IFN- $\alpha$ producing monocytes positively correlates with SLE disease activity (93). Interestingly, mTOR inhibition suppressed STING upregulation and IFN- $\alpha$ production in lupus monocytes (93). In mice, Fasdeficient lupus-prone MRL/Mp-lpr/lpr mice display systemic autoimmunity, massive lymphadenopathy, arthritis and immune complex glomerulonephrosis starting at about three months of age. Crossing these lupus-prone mice with Sting-deficient mice significantly increases autoimmunity and shortens lifespans (94). The authors further show that STING-mediated protection is IRF3independent (94). Furthermore, TLR-dependent systemic inflammation following 2,6,10,14-tetramethylpentadecane (TMPD) stimulation is exacerbated by STING deficiency which results in increased levels of pro-inflammatory cytokines and elevated numbers of myeloid cells (94).

\section{Familial Chilblain Lupus}

Familial chilblain lupus is a rare autosomal dominant form of cutaneous lupus erythematosus occurring mainly in young children, due to mutations in the TREX1 gene as well as in mutations within SAMHD1 or TMEM173 in rare cases $(95,96)$. In particular, G166E heterozygous mutation in TMEM173 was found in five patients with familial chilblain lupus resulting in constitutive type I IFN production, for which the Janus kinase (JAK) inhibitor tofacitinib showed promising results (95).

\section{CGAS/STING IN INFLAMMATORY DISEASES}

\section{Fibrosis}

STING pathway has been linked to the regulation of fibrotic processes in various tissues. Idiopathic pulmonary fibrosis (IPF) is characterized by progressive lung scarring punctuated by lifethreatening acute exacerbations causing shorter life expectancy and a high mortality rate (97-99). It is believed that the physiopathology relies on repetitive local micro-injuries leading to DNA damage, cell death and finally to an aberrant repair with deposition of extracellular matrix components and fibrosis (97-100). Using the classical murine model of human IPF by airway exposure to bleomycin (BLM), we published recently that STING deficiency leads to increased lung fibrosis in an unexpected type I IFNindependent manner indicating that STING plays a protective role in limiting experimental lung fibrosis (101). In line with our findings, a recent study in IPF patients showed that STING expression in PBMC decreases during acute exacerbation. STING protein levels post-treatment increased in patients showing clinical improvement but remained low in patients displaying clinical deterioration, strongly suggesting a benefic role of STING in IPF (102). Of note, elevated plasma mtDNA copy numbers in IPF patients predict death (103). A protective role of STING against fibrosis has also been shown is a model of chronic pancreatitis (104). Authors showed that STING deficiency promotes Th17 polarization and IL-17A production therefore pancreatic inflammation and fibrosis (104). 
On the other hand, Susztak et al. showed that patients suffering from chronic kidney disease (CKD) display defective mitochondrial integrity and further linked mtDNA release, STING activation and renal fibrosis (50). STING expression is upregulated in human and mouse hypertrophic hearts and STING deficiency leads to decreased inflammation and fibrosis in an ER stress-associated process (105). Inflammation-driven liver fibrosis upon carbon tetrachloride ( $\mathrm{CCl} 4)$ administration is a well-established model of chronic liver disease. It was shown that STING/IRF3 pathway mediates hepatocyte death and fibrosis independently of TLR and type I IFN signaling (106). Of note, the same group showed that STING is activated by alcohol-induced ER stress to trigger IRF3-dependent hepatocyte apoptosis, independently of type I IFN signaling (107). Chronic silica particles inhalation triggers silicosis, a lung disease with progressive interstitial fibrosis and increased risk of cancer. It was shown that airway silica exposure induces both nDNA and mtDNA release and STING-dependent type I IFN responses. Sting-deficient mice displayed significantly attenuated lung inflammation (108). Thus, STING contribution to fibrosis appears highly context/organ dependent and further studies are required to delineate the molecular mechanisms involved.

\section{Obesity-Related Diseases}

Chronic sterile inflammation in obesity and related metabolic diseases such as type 2 diabetes, nonalcoholic fatty liver disease (NAFLD) and cardiovascular disease have been widely demonstrated (109). A number of studies recently showed that selfDNA sensing, either nuclear or mitochondrial, plays important roles in these pathologies. Obesity promotes mtDNA release into the cytosol of adipocytes, which leads to cGAS-STING-mediated inflammation (51). Using methionine/choline-deficient diet (MCD) or high-fat diet (HFD) as murine models of non-alcoholic steatohepatitis (NASH), it was shown that STING/IRF3 pathway promotes hepatocyte injury and dysfunction by inducing inflammation and apoptosis as well as by disturbing glucose and lipid metabolism (110). Sting-deficient mice display reduced HFDinduced adipose tissue inflammation and insulin resistance (111). However, the cell subset(s) involved remain(s) unclear. A recent study confirmed that STING deficiency attenuated steatosis, fibrosis, and inflammation using both MCD and HFD murine models (52). However, they pointed out that in contrast to IRF3, several studies including theirs reported that STING protein is not expressed in hepatocytes of adult humans or mice. They showed that hepatocytes from HFD-fed mice release mtDNA which activates STING in Kupffer cells leading to TNF- $\alpha$ and IL-6 productions and pathology (52). The role of STING in hematopoietic-derived cells in driving HFD-induced NAFLD has been confirmed by bone marrow transfer experiments (112). However, STING role in nonimmune cells has also been confirmed. Adipose tissue chronic inflammation and metabolic stress in obesity induce endothelial inflammation, which plays a key role in insulin resistance. Obesityrelated increase in free fatty acid induces mitochondrial damage and mtDNA release, which activates the cGAS/STING pathway leading to IRF3-dependent upregulation of ICAM-1 expression and endothelial inflammation (111).

\section{Myocardial Infarction}

An elegant study showed that ischemic cell death and cell debris uptake by cardiac macrophages lead to cGAS/STING pathway activation and IRF3-mediated type I IFN production (113). As compared to WT relatives, myocardial infarction induction in Sting-deficient mice leads to decreased Ifnbl expression and a strong drop in Cxcl10, Irf7, and Ifit1 expressions (113). In contrast to about $50 \%$ mortality in WT mice, Irf3- or type I IFN receptor (Ifnar)-deficient mice showed virtually complete protection, whereas Cgas-deficient mice displayed partial protection and Sting-deficient mice did not reach statistical difference (113). These data suggest that other innate immune sensors are involved in IRF3 activation after myocardial infarction.

Upon myocardial infarction, cGAS induces iNOS and CXCL10 upregulation but not pro-inflammatory mediators such as IL-1 $\beta$, IL-18, TNF- $\alpha$ and IL-6 (114). Cgas-deficient mice display higher regulatory capacities, including $\mathrm{M}$ 2-like macrophages and myofibroblasts in the region bordering the myocardial infarction. cGAS deficiency also protects against myocardial infarction-induced adverse ventricular remodeling and rupture and enhances tissue repair in the infarct region (114). Of note, it was suggested that cGAS-mediated autophagy protects the liver from ischemia-reperfusion injury independently of STING (115).

\section{COPD}

Chronic obstructive pulmonary disease (COPD) is a major health issue primarily caused by cigarette smoke (CS) inhalation. It is characterized by chronic bronchitis and emphysema, i.e. long-term inflammation of the airways and irreversible destruction of the alveolar cell wall, respectively (116). Using an acute model of CS exposure in mice, we showed that CS increases self-DNA content in the alveolar space driving cGAS/STING-dependent neutrophilic influx and inflammatory response (117). DNAse I treatment reduces CS-induced lung inflammation by limiting deleterious effects of neutrophil extracellular traps (NETs) for instance in terms of protease expression (118). In contrast, sub-chronic CS exposure induces a reduction of STING lung expression impeding subsequent response to infection (119) and COPD patients display lower pulmonary IFN- $\beta$ expression (120). Lower IFN levels might in part contribute to the poor immune response to infection developed by COPD patients during exacerbation phases.

\section{CGAS/STING IN NEURODEGENERATIVE DISORDERS}

Over the past few years, a number of important studies showed potential strong involvement of the cGAS/STING pathway in neuroinflammatory processes and neurodegenerative disorders. STING regulates steady-state and nerve injury-triggered nociception through its signaling in sensory neurons (121). Intrathecal injection (i.e. into the spinal canal) of STING agonists leads to robust antinociception in mice and nonhuman primates (NHPs) in a type I IFN-mediated signaling on peripheral nociceptors (121). Sting or Ifnar-deficient mice exhibit hypersensitivity to nociceptive stimuli and increased 
nociceptor excitability. The exact mechanism of STING activation at steady state and following nerve damage remains to be determined, potentially implying cell death and selfDNA sensing.

Amyotrophic lateral sclerosis (ALS) is a neurodegenerative disease of the central nervous system (CNS) causing progressive loss of muscle control and often characterized by a cytotoxic accumulation of TAR DNA-binding protein 43 (TDP-43). TDP43 accumulation in the mitochondria induces DNA leakage and cGAS/STING pathway activation promoting inflammatory signaling and pathology (122). Using mouse models to investigate Parkinson's disease (PD) inflammatory profile, Sliter et al. showed that inflammation in Parkin $^{-/-}$and Pink1 $1^{-/-}$ mice undergoing exhaustive exercise is linked to mtDNA leakage and rescued in the absence of STING (123). Serum/ glucocorticoid related kinase 1 (SGK1) is upregulated in the brains of patients with various neurodegenerative disorders such as PD and pharmacological inhibition of SGK1 limits NLRP3inflammasome- and cGAS-STING-mediated inflammatory pathways (124). Employing PD mouse models, it was shown that the neuroprotective agent withaferin A protected against dopaminergic neuron loss in a STING-dependent manner (125).

The cGAS/STING pathway might also play a role in accelerated aging and neurodegeneration observed in Huntington's disease (HD). Melatonin, a radical scavenger expressed by neuronal mitochondria, decreases with aging and neurodegeneration. Melatonin-deficient mice display increased mtDNA release and activation the cGAS/STING/IRF3 pathway (126). Exogenous melatonin administration in R6/2 mice as a genetic mouse model of HD alleviates cGAS/STING-mediated inflammation (126). STING pathway inhibition may offer therapeutic benefits in $\mathrm{HD}$ by limiting deleterious upregulation of inflammatory and autophagy responses (127). Finally, cGAS/STING activation delayed neurodegeneration in neonatal hypoxia-ischemia in rats (128), however STINGmediated protective mechanism remains to be determined.

\section{CGAS/STING IN CANCER}

cGAS/STING pathway in cancer settings is under deep examination in both tumor cells as well as in neighboring immune and non-immune cells. Most tumors retain cGAS and STING expression (129) and cancer cell cGAS recognizing cytosolic DNA produces cGAMP inducing STING-dependent type-I IFN secretion (130). Acute STING activation is likely to exhibit type I IFN-mediated anti-tumor effect associated with cellular senescence and T lymphocyte-dependent immunity. In more advance stages, chromosomally unstable tumors become tolerant to chronic cGAS-STING signaling, downregulate downstream IFN signaling while maintaining alternative pathways that promote tumorigenesis (129). In mice, STING deficiency facilitates development of several types of tumors whereas STING stimulation favors antitumor immunity (41, 131, 132). Cytosolic DNA accumulation can result from the combined action of the endonuclease MUS81 and
PARP-dependent DNA repair as shown in prostate cancer cells, leading to STING-dependent tumor rejection (133). In contrast, by generating Sting ${ }^{\mathrm{S} 365 \mathrm{~A} / \mathrm{S} 365 \mathrm{~A}}$ mutant mouse strain that precisely ablates IFN-dependent activities, Wu et al. showed that T cells in tumors undergo substantial cell death in part mediated by IFN-independent STING activities promoting tumor evasion (134).

cGAS also elicits contrasting outcomes depending on the context. Carcinoma-derived cGAMP diffuses to astrocyte through connexin 43 (Cx43) gap junctions leading to STINGdependent IFN- $\alpha$ production acting in paracrine manner on metastatic cells to support chemoresistance and tumor growth through STAT1 activation (135). DNA repair following doublestranded breaks by homologous recombination prevents tumorigenesis. DNA damage induces nuclear translocation of cGAS where it inhibits homologous recombination and therefore promotes tumor growth (136). A recent publication showed that efferocytosis blockade by inhibiting MerTK-dependent apoptotic tumor cell phagocytosis promotes $\mathrm{CD}^{+} \mathrm{T}$ cell-mediated antitumor activity. Apoptotic tumor cells clearance failure leads to secondary necrosis accompanied with danger signals release. Among them, ATP and cGAMP activate P2X7 receptor and STING, respectively, in neighboring $\mathrm{CD}^{+} \mathrm{T}$ cells leading to enhanced type I IFN production-mediated immune activation and tumor suppression, especially at early stage (137).

Numerous studies targeting the STING pathway have been performed to address its potential use as antitumor. Intratumoral delivery of synthetic CDN derivatives induces STING-dependent tumor regression as well as metastases rejection and long-lived immunologic memory in a dose-dependent manner $(138,139)$. Intravenous $\mathrm{CDN}$ administration also increased survival rate in mice with acute myeloid leukemia (140). These results and others indicate potential strong benefit of targeting STING against different types of cancer. While clinical use of immune checkpoint blockade to promote anti-tumor immune responses proved to display tremendous benefit in several types of cancers (141-143), most patients do not show significant improvement when these checkpoint inhibitors are given as a monotherapy and thus require combined chemotherapy (143). Most chemotherapeutic agents non-specifically target dividing cells by blocking DNA replication leading to apoptosis (144). Besides a direct positive effect by killing tumors cells, cytotoxicity and danger signals induced by chemotherapeutic drugs can enhance the inflammatory environment and $\mathrm{CD}^{+} \mathrm{T}$ cell activation (145). Therefore, combining immunotherapy with additional targets including the cGAS/STING pathway constitutes an intense scope of investigation, recently reviewed (146). The potential ability of radiotherapy to enhance immunotherapy constitutes another field of investigation. While radiation doses above 12-18 Gy induce DNA exonuclease TREX1 and therefore dampen cGAS activity, repeated irradiation at lower doses ( 3 times $8 \mathrm{~Gy}$ ) does not induce TREX1 expression and leads to increased type I IFN production through the cGAS/STING pathway (147). In addition, Trex1 knockdown restores cytosolic dsDNA accumulation and ISG induction in a mouse model of mammary carcinoma refractory to immune checkpoint inhibitors (147). 
In summary, cGAS-STING-elicited outcome in cancer is largely context-dependent. Transient cGAS-STING activation in innate immune cells may display anti-tumor activity, whereas sustained activation might induce immune tolerance and tumor growth. The use of synthetic CDNs together with anti-cancer immunotherapy may be promising in response to certain types of cancers $(138,148)$.

\section{CELLULAR PROCESSES}

\section{STING and Autophagy}

Autophagy is a phylogenetically conserved catabolic process induced by numerous endogenous (e.g. nutrient deprivation) or exogenous (e.g. infection) cellular stress conditions aiming to either promote cell survival or apoptosis of senescent cells (149). Autophagy induction by STING has been first identified in the context of bacterial infection. Authors showed that $M$. tuberculosis DNA recognition induces STING-dependent targeting of bacteria and autophagy-mediated resistance to infection (31). More recent studies suggest that STINGdependent autophagy regulation may have evolved before type I IFN induction. In invertebrates such as the sea anemone Nematostella vectensis, STING protein does not harbor the two C-terminal tail (CTT) domains critical to activate IRF3 but effectively induces autophagy (30). STING triggers autophagy in a TBK1- and type I IFN-independent manner (32). Upon activation, STING binds to the autophagy inducing protein LC3 promoting both autophagy and STING degradation (32), therefore regulating STING-mediated immune activation. cGAMP binding induces STING translocation to the endoplasmic reticulum-Golgi intermediate compartment (ERGIC) and the Golgi. STING-containing ERGIC serves as a membrane source for LC3 lipidation and autophagasome formation. This form of autophagy, important for the clearance of cytosolic DNA, is mediated by autophagy-related gene 5 (ATG5) and Trp-Asp (W-D) repeat domain phosphoinositide-interacting protein (WIPI2) (30). Furthermore, cGAS protects hepatocytes by triggering autophagy independently of STING in mouse models of ischemia-reperfusion (115).

Cell death following replicative crisis is a senescenceindependent process important to prevent oncogenic transformation of pre-cancerous cells with disrupted cell cycle checkpoints. It was shown that cytosolic DNA activates the cGAS/STING pathway to promote macroautophagy and autophagic cell death (150). Of note, STING signaling is negatively regulated by p62/SQSTM1-dependent autophagy pathway activated by TBK1 (151).

Circulating mtDNA levels and STING activation profile are increased in sepsis-induced acute lung injury (ALI) patients (152). In a mouse model of sepsis, mtDNA-triggered STINGmediated IFN production interferes with autophagy by preventing lysosomal acidification and thus worsens pathology (152). STING-dependent autophagy upregulation observed in the striatum of HD patients favors brain damage (127). Radiotherapy-induced mtDNA release facilitates cGAS/STING activation and type I IFN-mediated antitumor responses and autophagy induction limits this effect (153). Patients with breast cancer showing increased genetic autophagy signature in the tumor microenvironment display slightly decreased survival prognostic, inversely correlating with mitochondrial abundance and type I IFN signaling (153).

\section{CGAS/STING and Cell Death}

There is a finely regulated and context-dependent cross-talk between several cell death processes and the cGAS/STING pathway. The latter is often inhibited during apoptotic processes to limit inflammation. During cell intrinsic apoptosis, mitochondrial outer membrane permeabilization (MOMP) leads to mtDNA release but concomitantly to caspase- 9 and caspase- 3 which display immunosuppressive function by repressing the cGAS/STING/type I IFN pathway $(154,155)$. It was recently shown that caspase- 9 and caspase- 3 directly cleave cGAS and IRF3 to limit STING activation and deleterious inflammation (156). In contrast, cGAS-STING pathway initiates certain form of programmed cell death. Nucleosomes competitively inhibit DNA-dependent cGAS activation during regular mitotic processes. However, during mitotic arrest limited cGAS activation leads to mild STINGdependent IRF3 phosphorylation triggering mitotic aberrations and transcription-independent induction of apoptosis (157). In addition, host restriction factor SAMHD1 limits human $\mathrm{T}$ cell leukemia virus type 1 infection of monocytes via STINGmediated apoptosis and viral products interact with STING to trigger an IRF3-Bax complex leading to apoptosis (158). Noteworthy, T lymphocytes exhibit an intensified STING response predisposing them to apoptosis (34). This effect does not appear to occur in other cell types including dendritic cells and macrophages, presumably owing higher STING expression and signaling in $\mathrm{T}$ cells as compared to other cell subsets (34).

Gaidt et al. showed that STING traffics through the Golgi and then through late endosomes and lysosomes (33). The precise location of STING, e.g. at the outer lysosomal membrane or within multivesicular bodies, remains to be determined. STING in lysosomes induces lysosomal membrane destabilization leading to the release of proteases such as cathepsins triggering lysosomal cell death (LCD) $(33,159)$, however the mechanism involved remains to be established. Furthermore, it appears that the main function of STING targeting to the lysosome is its degradation to limit its activity (160). Necroptosis is a regulated form of necrotic cell death governed by RIP1/RIP3-mediated activation of MLKL. During necroptosis, the proapoptotic $\mathrm{BH} 3-$ only BCL-2 family member PUMA is transcriptionally activated in an RIP3/MLKL-dependent manner. PUMA promotes the cytosolic release of mtDNA which activates DAI/Zbp1 and STING leading to enhanced RIP3 and MLKL phosphorylation in a positive feedback loop and thus amplifies necroptosis (35). Interestingly, basal cytosolic DNA sensing by the cGAS/STING pathway is important for constitutive type I IFN production and signaling, maintaining baseline ISG induction. It was shown that this phenomenon is critical to reach a critical threshold of MLKL for LPS-dependent necroptosis (161). 


\section{CGAS/STING and Chromosomal Instability/Senescence}

Chromosomal instability is a hallmark of cancer in human, associated with poor prognosis, metastasis, and therapeutic failure (129). It results from errors in chromosome segregation during mitosis and can cause micronuclei formation in the cytoplasm. During metazoan cell division, the nuclear envelope is ruptured and if the exposed chromatin is not entirely contained within the daughter cells nuclei, it can be encapsulated within independent structures called micronuclei. Micronuclei rupture leads to cytosolic self-DNA release and cGAS activation $(17,48)$. DNA damage induced by monogenic autoinflammation (e.g. Rnaseh $2 b$ deficiency) or exogenous DNA damage (e.g. ionizing radiation) leads to micronuclei formation which rupture activates cGAS leading to ISG expression (17). This pathway is also involved in the context of genotoxic cancer therapy where STING-dependent responses display antitumor activities (48). A recent article showed that chromosomal instability leads to increased numbers of micronuclei and cytosolic DNA, which activate the cGAS-STING pathway (162). Rather than engaging type I IFN or canonical NF- $\kappa \mathrm{B}$ pathways, STING activates noncanonical NF- $\mathrm{KB}$ signaling linked to the upregulation of epithelial-mesenchymal transition (EMT) and inflammatory genes, therefore enhancing cell migratory capacity and metastasis (162).

cGAS has been shown to be a critical inducer of cellular senescence, a form of terminal cell-cycle arrest associated with pro-inflammatory response which prevents tumorigenesis and participates to the antitumor effects of radio- and chemotherapies (163). cGAS binds to cytosolic chromatin fragments in senescent cells and induces STING-dependent production of senescence-associated secretory phenotype (SASP) inflammatory mediators promoting paracrine senescence (164). Cytoplasmic chromatin fragments are pinched off intact nuclei during senescence to activate the cGAS-STING pathway (165).

Progeria, or Hutchinson-Gilford progeria syndrome (HGPS), is a rare autosomal dominant condition beginning in childhood with striking phenotypic features of premature aging. It is caused by a truncated lamin A protein (progerin) inducing nuclear envelope fragility and genomic instability and fatal senescence. Progerin-mediated DNA release leads to the upregulation of the cGAS/STING pathway and pathogenic type IFN response (166).

\section{STING and Inflammasome}

Cytosolic DNA-mediated cGAS/STING activation leads to STING trafficking to the lysosome, where it triggers membrane permeabilization and potassium efflux which activate the NLRP3 inflammasome (33). Non-canonical functions of cGAMP in regulating both priming and activation steps of the

\section{REFERENCES}

1. Janeway CA Jr. Approaching the Asymptote? Evolution and Revolution in Immunology. Cold Spring Harbor Symp Quant Biol (1989) 54:1-13. doi: 10.1101/SQB.1989.054.01.003 inflammasome have been reported. cGAS-derived cGAMP induces type I IFN induction via STING leading to increased expression of inflammasome components and cGAMP also favors inflammasome activity by promoting complexes containing both NLRP3 and AIM2 (167). Using protein overexpression assays, it was recently shown that Herpes Simplex Virus-1 (HSV-1) infection or cytosolic DNA stimulation triggers STING binding to NLRP3, promoting both NLRP3 localization in the ER and attenuating NLRP3 polyubiquitination and degradation (168). In addition, IL-1 $\beta$ signaling on human myeloid, fibroblast, and epithelial cells induce mtDNA release to activate innate immune signaling via cGAS-STING (169) and mtDNA-driven cGAS activation triggers age-related macular degeneration through STING-mediated non-canonical inflammasome pathway involving IFN- $\beta$ (170).

\section{CONCLUSION}

Our understanding of the mechanisms of danger signal release and sensing has evolved considerably over the last years. It now becomes clear that misplaced self-DNA is a potent trigger of immune activation through various DNA sensing machinery. Among them, the cGAS/STING pathway has emerged as an important source of type I and type III interferons as well as a critical regulator of cellular processes such as autophagy and programmed cell death. Targeting the STING pathway may offer tremendous therapeutic opportunities, not only in response to infection as recently illustrated with SARS-CoV-2 infection (171, 172) but also in inflammatory conditions and cancer settings. In addition, natural and synthetic CDNs are used as adjuvants to enhance protective humoral and $\mathrm{CD}^{+}$and $\mathrm{CD}^{+} \mathrm{T}$ cells responses in a STING-dependent manner (173-176).

\section{AUTHOR CONTRIBUTIONS}

Review was written by IC and NR. Figures were prepared by NR. All authors contributed to the article and approved the submitted version.

\section{FUNDING}

This work was supported by the Centre National de la Recherche Scientifique (CNRS), the University of Orleans, The Region Centre Val de Loire (2003-00085470), the 'Conseil Général du Loiret', 'Fondation pour la Recherche Médicale' (EQU202003010405) and the European Regional Development Fund (FEDER N²01600110366 and EX005756).

2. Akira S, Uematsu S, Takeuchi O. Pathogen Recognition and Innate Immunity. Cell (2006) 124:783-801. doi: 10.1016/j.cell.2006.02.015

3. Chen GY, Nunez G. Sterile Inflammation: Sensing and Reacting to Damage. Nat Rev Immunol (2010) 10:826-37. doi: 10.1038/ nri2873 
4. Ablasser A, Hertrich C, Wassermann R, Hornung V. Nucleic Acid Driven Sterile Inflammation. Clin Immunol (2013) 147:207-15. doi: 10.1016/ j.clim.2013.01.003

5. West AP, Shadel GS. Mitochondrial DNA in Innate Immune Responses and Inflammatory Pathology. Nat Rev Immunol (2017) 17:363-75. doi: 10.1038/ nri.2017.21

6. Barber GN. STING: Infection, Inflammation and Cancer. Nat Rev Immunol (2015) 15:760-70. doi: 10.1038/nri3921

7. Matzinger P. Introduction to the Series. Danger Model of Immunity. Scand $J$ Immunol (2001) 54:2-3. doi: 10.1046/j.1365-3083.2001.00973.x

8. Ishikawa H, Barber GN. STING Is an Endoplasmic Reticulum Adaptor That Facilitates Innate Immune Signalling. Nature (2008) 455:674-8. doi: 10.1038/nature07317

9. Zhong B, Yang Y, Li S, Wang YY, Li Y, Diao F, et al. The Adaptor Protein MITA Links Virus-Sensing Receptors to IRF3 Transcription Factor Activation. Immunity (2008) 29:538-50. doi: 10.1016/j.immuni.2008.09.003

10. Jin L, Waterman PM, Jonscher KR, Short CM, Reisdorph NA, Cambier JC. MPYS, a Novel Membrane Tetraspanner, Is Associated With Major Histocompatibility Complex Class II and Mediates Transduction of Apoptotic Signals. Mol Cell Biol (2008) 28:5014-26. doi: 10.1128/MCB.00640-08

11. Sauer JD, Sotelo-Troha K, von Moltke J, Monroe KM, Rae CS, Brubaker SW, et al. The N-Ethyl-N-Nitrosourea-Induced Goldenticket Mouse Mutant Reveals an Essential Function of Sting in the In Vivo Interferon Response to Listeria Monocytogenes and Cyclic Dinucleotides. Infect Immun (2011) 79:688-94. doi: 10.1128/IAI.00999-10

12. Burdette DL, Monroe KM, Sotelo-Troha K, Iwig JS, Eckert B, Hyodo M, et al. STING Is a Direct Innate Immune Sensor of Cyclic Di-GMP. Nature (2011) 478:515-8. doi: 10.1038/nature10429

13. Diner EJ, Burdette DL, Wilson SC, Monroe KM, Kellenberger CA, Hyodo M, et al. The Innate Immune DNA Sensor cGAS Produces a Noncanonical Cyclic Dinucleotide That Activates Human STING. Cell Rep (2013) 3:135561. doi: 10.1016/j.celrep.2013.05.009

14. Wu J, Sun L, Chen X, Du F, Shi H, Chen C, et al. Cyclic GMP-AMP Is an Endogenous Second Messenger in Innate Immune Signaling by Cytosolic DNA. Science (2013) 339:826-30. doi: 10.1126/science.1229963

15. Sun L, Wu J, Du F, Chen X, Chen ZJ. Cyclic GMP-AMP Synthase Is a Cytosolic DNA Sensor That Activates the Type I Interferon Pathway. Science (2013) 339:786-91. doi: 10.1126/science.1232458

16. Ablasser A, Chen ZJ. cGAS in Action: Expanding Roles in Immunity and Inflammation. Science (2019) 363(6431):eaat8657. doi: 10.1126/ science.aat 8657

17. Mackenzie KJ, Carroll P, Martin CA, Murina O, Fluteau A, Simpson DJ, et al. cGAS Surveillance of Micronuclei Links Genome Instability to Innate Immunity. Nature (2017) 548:461-5. doi: 10.1038/nature23449

18. Carroll EC, Jin L, Mori A, Munoz-Wolf N, Oleszycka E, Moran HBT, et al. The Vaccine Adjuvant Chitosan Promotes Cellular Immunity via DNA Sensor cGAS-STING-Dependent Induction of Type I Interferons. Immunity (2016) 44:597-608. doi: 10.1016/j.immuni.2016.02.004

19. Zhang X, Wu J, Du F, Xu H, Sun L, Chen Z, et al. The Cytosolic DNA Sensor cGAS Forms an Oligomeric Complex With DNA and Undergoes SwitchLike Conformational Changes in the Activation Loop. Cell Rep (2014) 6:42130. doi: $10.1016 /$ j.celrep.2014.01.003

20. Li X, Shu C, Yi G, Chaton CT, Shelton CL, Diao J, et al. Cyclic GMP-AMP Synthase Is Activated by Double-Stranded DNA-Induced Oligomerization. Immunity (2013) 39:1019-31. doi: 10.1016/j.immuni.2013.10.019

21. Barnett KC, Coronas-Serna JM, Zhou W, Ernandes MJ, Cao A, Kranzusch $\mathrm{PJ}$, et al. Phosphoinositide Interactions Position cGAS at the Plasma Membrane to Ensure Efficient Distinction Between Self- and Viral DNA. Cell (2019) 176:1432-46.e1411. doi: 10.1016/j.cell.2019.01.049

22. Lahaye X, Gentili M, Silvin A, Conrad C, Picard L, Jouve M, et al. NONO Detects the Nuclear HIV Capsid to Promote cGAS-Mediated Innate Immune Activation. Cell (2018) 175:488-501.e422. doi: 10.1016/j.cell.2018.08.062

23. Volkman HE, Cambier S, Gray EE, Stetson DB. Tight Nuclear Tethering of cGAS Is Essential for Preventing Autoreactivity. Elife (2019) 8:e47491. doi: 10.7554/eLife.47491

24. Cao D, Han X, Fan X, Xu RM, Zhang X. Structural Basis for NucleosomeMediated Inhibition of cGAS Activity. Cell Res (2020) 30:1088-97. doi: $10.1038 /$ s41422-020-00422-4
25. Dunphy G, Flannery SM, Almine JF, Connolly DJ, Paulus C, Jonsson KL, et al. Non-Canonical Activation of the DNA Sensing Adaptor STING by ATM and IFI16 Mediates NF-kappaB Signaling After Nuclear DNA Damage. Mol Cell (2018) 71:745-60.e745. doi: 10.1016/j.molcel.2018.07.034

26. West AP, Khoury-Hanold W, Staron M, Tal MC, Pineda CM, Lang SM, et al. Mitochondrial DNA Stress Primes the Antiviral Innate Immune Response. Nature (2015) 520:553-7. doi: 10.1038/nature14156

27. Blaauboer SM, Mansouri S, Tucker HR, Wang HL, Gabrielle VD, Jin L. The Mucosal Adjuvant Cyclic Di-GMP Enhances Antigen Uptake and Selectively Activates Pinocytosis-Efficient Cells In Vivo. Elife (2015) 4:e06670. doi: 10.7554/eLife.06670

28. Kim JA, Park SK, Seo SW, Lee CH, Shin OS. STING Is Involved in Antiviral Immune Response Against VZV Infection via the Induction of Type I and III IFN Pathways. J Invest Dermatol (2017) 137:2101-9. doi: 10.1016/ j.jid.2017.03.041

29. Sui H, Zhou M, Imamichi H, Jiao X, Sherman BT, Lane HC, et al. STING Is an Essential Mediator of the Ku70-Mediated Production of IFN-Lambda1 in Response to Exogenous DNA. Sci Signal (2017) 10:eaah5054. doi: 10.1126/ scisignal.aah5054

30. Gui X, Yang H, Li T, Tan X, Shi P, Li M, et al. Autophagy Induction via STING Trafficking Is a Primordial Function of the cGAS Pathway. Nature (2019) 567:262-6. doi: 10.1038/s41586-019-1006-9

31. Watson RO, Manzanillo PS, Cox JS. Extracellular M. Tuberculosis DNA Targets Bacteria for Autophagy by Activating the Host DNA-Sensing Pathway. Cell (2012) 150:803-15. doi: 10.1016/j.cell.2012.06.040

32. Liu D, Wu H, Wang C, Li Y, Tian H, Siraj S, et al. STING Directly Activates Autophagy to Tune the Innate Immune Response. Cell Death Differ (2019) 26:1735-49. doi: 10.1038/s41418-018-0251-z

33. Gaidt MM, Ebert TS, Chauhan D, Ramshorn K, Pinci F, Zuber S, et al. The DNA Inflammasome in Human Myeloid Cells Is Initiated by a STING-Cell Death Program Upstream of NLRP3. Cell (2017) 171:1110-24.e1118. doi: 10.1016/j.cell.2017.09.039

34. Gulen MF, Koch U, Haag SM, Schuler F, Apetoh L, Villunger A, et al. Signalling Strength Determines Proapoptotic Functions of STING. Nat Commun (2017) 8:427. doi: 10.1038/s41467-017-00573-w

35. Chen D, Tong J, Yang L, Wei L, Stolz DB, Yu J, et al. PUMA Amplifies Necroptosis Signaling by Activating Cytosolic DNA Sensors. Proc Natl Acad Sci USA (2018) 115:3930-5. doi: 10.1073/pnas.1717190115

36. Lee KG, Kim SS, Kui L, Voon DC, Mauduit M, Bist P, et al. Bruton's Tyrosine Kinase Phosphorylates DDX41 and Activates Its Binding of dsDNA and STING to Initiate Type 1 Interferon Response. Cell Rep (2015) 10:1055-65. doi: 10.1016/j.celrep.2015.01.039

37. Parvatiyar K, Zhang Z, Teles RM, Ouyang S, Jiang Y, Iyer SS, et al. The Helicase DDX41 Recognizes the Bacterial Secondary Messengers Cyclic DiGMP and Cyclic Di-AMP to Activate a Type I Interferon Immune Response. Nat Immunol (2012) 13:1155-61. doi: 10.1038/ni.2460

38. Ishikawa H, Ma Z, Barber GN. STING Regulates Intracellular DNAMediated, Type I Interferon-Dependent Innate Immunity. Nature (2009) 461:788-92. doi: 10.1038/nature08476

39. Dey B, Dey RJ, Cheung LS, Pokkali S, Guo H, Lee JH, et al. A Bacterial Cyclic Dinucleotide Activates the Cytosolic Surveillance Pathway and Mediates Innate Resistance to Tuberculosis. Nat Med (2015) 21:401-6. doi: 10.1038/nm.3813

40. Konno H, Yamauchi S, Berglund A, Putney RM, Mule JJ, Barber GN. Suppression of STING Signaling Through Epigenetic Silencing and Missense Mutation Impedes DNA Damage Mediated Cytokine Production. Oncogene (2018) 37:2037-51. doi: 10.1038/s41388-017-0120-0

41. Woo SR, Fuertes MB, Corrales L, Spranger S, Furdyna MJ, Leung MY, et al. STING-Dependent Cytosolic DNA Sensing Mediates Innate Immune Recognition of Immunogenic Tumors. Immunity (2014) 41:830-42. doi: 10.1016/j.immuni.2014.10.017

42. Souza-Fonseca-Guimaraes F, Parlato M, de Oliveira RB, Golenbock D, Fitzgerald $\mathrm{K}$, Shalova IN, et al. Interferon- $\gamma$ and Granulocyte/Monocyte Colony-Stimulating Factor Production by Natural Killer Cells Involves Different Signaling Pathways and the Adaptor Stimulator of Interferon Genes (STING). J Biol Chem (2013) 288:10715-21. doi: 10.1074/ jbc.M112.435602

43. Larkin B, Ilyukha V, Sorokin M, Buzdin A, Vannier E, Poltorak A. Cutting Edge: Activation of STING in T Cells Induces Type I IFN Responses and Cell 
Death. J Immunol (Baltimore Md: 1950) (2017) 199:397-402. doi: 10.4049/ jimmunol.1601999

44. Walker MM, Crute BW, Cambier JC, Getahun A. B Cell-Intrinsic STING Signaling Triggers Cell Activation, Synergizes With B Cell Receptor Signals, and Promotes Antibody Responses. J Immunol (Baltimore Md: 1950) (2018) 201:2641-53. doi: 10.4049/jimmunol.1701405

45. Anastasiou M, Newton GA, Kaur K, Carrillo-Salinas FJ, Smolgovsky SA, Bayer AL, et al. Endothelial STING Controls T Cell Transmigration in an IFNI-Dependent Manner. JCI Insight (2021) 6(15):e149346. doi: 10.1172/ jci.insight. 149346

46. Yu Y, Yang W, Bilotta AJ, Yu Y, Zhao X, Zhou Z, et al. STING Controls Intestinal Homeostasis Through Promoting Antimicrobial Peptide Expression in Epithelial Cells. FASEB J (2020) 34:15417-30. doi: 10.1096/ fj.202001524R

47. Nazmi A, Mukhopadhyay R, Dutta K, Basu A. STING Mediates Neuronal Innate Immune Response Following Japanese Encephalitis Virus Infection. Sci Rep (2012) 2:347. doi: 10.1038/srep00347

48. Harding SM, Benci JL, Irianto J, Discher DE, Minn AJ, Greenberg RA. Mitotic Progression Following DNA Damage Enables Pattern Recognition Within Micronuclei. Nature (2017) 548:466-70. doi: 10.1038/nature23470

49. Pal S, Rao GN, Pal A. High Glucose-Induced ROS Accumulation Is a Critical Regulator of ERK1/2-Akt-tuberin-mTOR Signalling in RGC-5 Cells. Life Sci (2020) 256:117914. doi: 10.1016/j.lfs.2020.117914

50. Chung KW, Dhillon P, Huang S, Sheng X, Shrestha R, Qiu C, et al. Mitochondrial Damage and Activation of the STING Pathway Lead to Renal Inflammation and Fibrosis. Cell Metab (2019) 30(4):P784-99.E5. doi: 10.1016/j.cmet.2019.08.003

51. Bai J, Cervantes C, Liu J, He S, Zhou H, Zhang B, et al. DsbA-L Prevents Obesity-Induced Inflammation and Insulin Resistance by Suppressing the mtDNA Release-Activated cGAS-cGAMP-STING Pathway. Proc Natl Acad Sci USA (2017) 114:12196-201. doi: 10.1073/pnas.1708744114

52. Yu Y, Liu Y, An W, Song J, Zhang Y, Zhao X. STING-Mediated Inflammation in Kupffer Cells Contributes to Progression of Nonalcoholic Steatohepatitis. J Clin Invest (2019) 129:546-55. doi: 10.1172/JCI121842

53. Ahn J, Xia T, Rabasa Capote A, Betancourt D, Barber GN. Extrinsic Phagocyte-Dependent STING Signaling Dictates the Immunogenicity of Dying Cells. Cancer Cell (2018) 33:862-73.e865. doi: 10.1016/j.ccell. 2018.03.027

54. Ahn J, Gutman D, Saijo S, Barber GN. STING Manifests Self DNADependent Inflammatory Disease. Proc Natl Acad Sci USA (2012) 109:19386-91. doi: 10.1073/pnas.1215006109

55. Porat A, Giat E, Kowal C, He M, Son M, Latz E, et al. DNA-Mediated Interferon Signature Induction by SLE Serum Occurs in Monocytes Through Two Pathways: A Mechanism to Inhibit Both Pathways. Front Immunol (2018) 9:2824. doi: 10.3389/fimmu.2018.02824

56. Chamilos G, Gregorio J, Meller S, Lande R, Kontoyiannis DP, Modlin RL, et al. Cytosolic Sensing of Extracellular Self-DNA Transported Into Monocytes by the Antimicrobial Peptide LL37. Blood (2012) 120:3699707. doi: 10.1182/blood-2012-01-401364

57. Poli C, Augusto JF, Dauve J, Adam C, Preisser L, Larochette V, et al. IL-26 Confers Proinflammatory Properties. J Immunol (Baltimore Md: 1950) (2017) 198:3650-61. doi: 10.4049/jimmunol.1600594

58. Diamond JM, Vanpouille-Box C, Spada S, Rudqvist NP, Chapman JR, Ueberheide BM, et al. Exosomes Shuttle TREX1-Sensitive IFN-Stimulatory dsDNA From Irradiated Cancer Cells to DCs. Cancer Immunol Res (2018) 6:910-20. doi: 10.1158/2326-6066.CIR-17-0581

59. Lande R, Lee EY, Palazzo R, Marinari B, Pietraforte I, Santos GS, et al. CXCL4 Assembles DNA Into Liquid Crystalline Complexes to Amplify TLR9-Mediated Interferon- $\alpha$ Production in Systemic Sclerosis. Nat Commun (2019) 10:1731. doi: 10.1038/s41467-019-09683-z

60. Di Domizio J, Belkhodja C, Chenuet P, Fries A, Murray T, Mondéjar PM, et al. The Commensal Skin Microbiota Triggers Type I IFN-Dependent Innate Repair Responses in Injured Skin. Nat Immunol (2020) 21:1034-45. doi: 10.1038/s41590-020-0721-6

61. Ablasser A, Schmid-Burgk JL, Hemmerling I, Horvath GL, Schmidt T, Latz E, et al. Cell Intrinsic Immunity Spreads to Bystander Cells via the Intercellular Transfer of cGAMP. Nature (2013) 503:530-4. doi: 10.1038/ nature 12640
62. Marcus A, Mao AJ, Lensink-Vasan M, Wang L, Vance RE, Raulet DH. Tumor-Derived cGAMP Triggers a STING-Mediated Interferon Response in Non-Tumor Cells to Activate the NK Cell Response. Immunity (2018) 49:754-63.e754. doi: 10.1016/j.immuni.2018.09.016

63. Yi G, Brendel VP, Shu C, Li P, Palanathan S, Cheng Kao C. Single Nucleotide Polymorphisms of Human STING can Affect Innate Immune Response to Cyclic Dinucleotides. PloS One (2013) 8:e77846. doi: 10.1371/ journal.pone.0077846

64. Jin L, Xu LG, Yang IV, Davidson EJ, Schwartz DA, Wurfel MM, et al. Identification and Characterization of a Loss-of-Function Human MPYS Variant. Genes Immun (2011) 12:263-9. doi: 10.1038/gene.2010.75

65. Patel S, Blaauboer SM, Tucker HR, Mansouri S, Ruiz-Moreno JS, Hamann L, et al. The Common R71H-G230A-R293Q Human TMEM173 Is a Null Allele. J Immunol (Baltimore Md: 1950) (2017) 198:776-87. doi: 10.4049/ jimmunol.1601585

66. Zhang X, Shi H, Wu J, Zhang X, Sun L, Chen C, et al. Cyclic GMP-AMP Containing Mixed Phosphodiester Linkages Is an Endogenous High-Affinity Ligand for STING. Mol Cell (2013) 51:226-35. doi: 10.1016/j.molcel. 2013.05.022

67. Hamann L, Szwed M, Mossakowska M, Chudek J, Puzianowska-Kuznicka M. First Evidence for STING SNP R293Q Being Protective Regarding Obesity-Associated Cardiovascular Disease in Age-Advanced Subjects - A Cohort Study. Immun Ageing (2020) 17:7. doi: 10.1186/s12979-020-00176-y

68. Hamann L, Ruiz-Moreno JS, Szwed M, Mossakowska M, Lundvall L, Schumann RR, et al. STING SNP R293Q Is Associated With a Decreased Risk of Aging-Related Diseases. Gerontology (2019) 65:145-54. doi: 10.1159/ 000492972

69. Liu Y, Jesus AA, Marrero B, Yang D, Ramsey SE, Sanchez GAM, et al. Activated STING in a Vascular and Pulmonary Syndrome. New Engl J Med (2014) 371:507-18. doi: 10.1056/NEJMoa1312625

70. Jeremiah N, Neven B, Gentili M, Callebaut I, Maschalidi S, Stolzenberg MC, et al. Inherited STING-Activating Mutation Underlies a Familial Inflammatory Syndrome With Lupus-Like Manifestations. J Clin Invest (2014) 124:5516-20. doi: 10.1172/JCI79100

71. Clarke SL, Pellowe EJ, de Jesus AA, Goldbach-Mansky R, Hilliard TN, Ramanan AV. Interstitial Lung Disease Caused by STING-Associated Vasculopathy With Onset in Infancy. Am J Respir Crit Care Med (2016) 194:639-42. doi: 10.1164/rccm.201510-2102LE

72. Bouis D, Kirstetter P, Arbogast F, Lamon D, Delgado V, Jung S, et al. Severe Combined Immunodeficiency in Stimulator of Interferon Genes (STING) V154M/wild-Type Mice. J Allergy Clin Immunol (2019) 143:712-25.e715. doi: 10.1016/j.jaci.2018.04.034

73. Warner JD, Irizarry-Caro RA, Bennion BG, Ai TL, Smith AM, Miner CA, et al. STING-Associated Vasculopathy Develops Independently of IRF3 in Mice. J Exp Med (2017) 214:3279-92. doi: 10.1084/jem.20171351

74. Bennion BG, Ingle H, Ai TL, Miner CA, Platt DJ, Smith AM, et al. A Human Gain-Of-Function STING Mutation Causes Immunodeficiency and Gammaherpesvirus-Induced Pulmonary Fibrosis in Mice. J Virol (2019) 93:e01806-18. doi: 10.1128/JVI.01806-18

75. Luksch H, Stinson WA, Platt DJ, Qian W, Kalugotla G, Miner CA, et al. STINGAssociated Lung Disease in Mice Relies on T Cells But Not Type I Interferon. J Allergy Clin Immunol (2019) 144(1):P254-66.E8. doi: 10.1016/j.jaci.2019.01.044

76. Ellis NA, Groden J, Ye TZ, Straughen J, Lennon DJ, Ciocci S, et al. The Bloom's Syndrome Gene Product Is Homologous to RecQ Helicases. Cell (1995) 83:655-66. doi: 10.1016/0092-8674(95)90105-1

77. Gratia M, Rodero MP, Conrad C, Bou Samra E, Maurin M, Rice GI, et al. Bloom Syndrome Protein Restrains Innate Immune Sensing of Micronuclei by cGAS. J Exp Med (2019) 216:1199-213. doi: 10.1084/jem.20181329

78. Lemos H, Huang L, Chandler PR, Mohamed E, Souza GR, Li L, et al. Activation of the STING Adaptor Attenuates Experimental Autoimmune Encephalitis. J Immunol (Baltimore Md: 1950) (2014) 192:5571-8. doi: 10.4049/jimmunol.1303258

79. Mathur V, Burai R, Vest RT, Bonanno LN, Lehallier B, Zardeneta ME, et al. Activation of the STING-Dependent Type I Interferon Response Reduces Microglial Reactivity and Neuroinflammation. Neuron (2017) 96:1290302.e1296. doi: 10.1016/j.neuron.2017.11.032

80. Lemos H, Mohamed E, Huang L, Chandler PR, Ou R, Pacholczyk R, et al. Stimulator of Interferon Genes Agonists Attenuate Type I Diabetes 
Progression in NOD Mice. Immunology (2019) 158:353-61. doi: 10.1111/ imm. 13122

81. Zentsova I, Parackova Z, Kayserova J, Palova-Jelinkova L, Vrabcova P, Volfova N, et al. Monocytes Contribute to DNA Sensing Through the TBK1 Signaling Pathway in Type 1 Diabetes Patients. J Autoimmun (2019) 105:102294. doi: 10.1016/j.jaut.2019.06.005

82. Paludan SR, Bowie AG. Immune Sensing of DNA. Immunity (2013) 38:87080. doi: 10.1016/j.immuni.2013.05.004

83. Pelka K, Shibata T, Miyake K, Latz E. Nucleic Acid-Sensing TLRs and Autoimmunity: Novel Insights From Structural and Cell Biology. Immunol $\operatorname{Rev}(2016)$ 269:60-75. doi: 10.1111/imr.12375

84. Yan N. Immune Diseases Associated With TREX1 and STING Dysfunction. J Interferon Cytokine Res (2017) 37:198-206. doi: 10.1089/jir.2016.0086

85. Rice GI, Rodero MP, Crow YJ. Human Disease Phenotypes Associated With Mutations in TREX1. J Clin Immunol (2015) 35:235-43. doi: 10.1007/ s10875-015-0147-3

86. Morita M, Stamp G, Robins P, Dulic A, Rosewell I, Hrivnak G, et al. GeneTargeted Mice Lacking the Trex1 (DNase III) $3^{\prime} \rightarrow>5$ ' DNA Exonuclease Develop Inflammatory Myocarditis. Mol Cell Biol (2004) 24:6719-27. doi: 10.1128/MCB.24.15.6719-6727.2004

87. Stetson DB, Ko JS, Heidmann T, Medzhitov R. Trex1 Prevents Cell-Intrinsic Initiation of Autoimmunity. Cell (2008) 134:587-98. doi: 10.1016/ j.cell.2008.06.032

88. Kawane K, Fukuyama H, Kondoh G, Takeda J, Ohsawa Y, Uchiyama Y, et al. Requirement of DNase II for Definitive Erythropoiesis in the Mouse Fetal Liver. Science (2001) 292:1546-9. doi: 10.1126/science.292. 5521.1546

89. Gao D, Li T, Li XD, Chen X, Li QZ, Wight-Carter M, et al. Activation of Cyclic GMP-AMP Synthase by Self-DNA Causes Autoimmune Diseases. Proc Natl Acad Sci USA (2015) 112:E5699-705. doi: 10.1073/ pnas. 1516465112

90. Gall A, Treuting P, Elkon KB, Loo YM, Gale MJr., Barber GN, et al. Autoimmunity Initiates in Nonhematopoietic Cells and Progresses via Lymphocytes in an Interferon-Dependent Autoimmune Disease. Immunity (2012) 36:120-31. doi: 10.1016/j.immuni.2011.11.018

91. Pokatayev V, Hasin N, Chon H, Cerritelli SM, Sakhuja K, Ward JM, et al. RNase H2 Catalytic Core Aicardi-Goutieres Syndrome-Related Mutant Invokes cGAS-STING Innate Immune-Sensing Pathway in Mice. $J$ Exp Med (2016) 213:329-36. doi: 10.1084/jem.20151464

92. An J, Durcan L, Karr RM, Briggs TA, Rice GI, Teal TH, et al. Expression of Cyclic GMP-AMP Synthase in Patients With Systemic Lupus Erythematosus. Arthritis Rheumatol (Hoboken NJ) (2017) 69:800-7. doi: $10.1002 /$ art. 40002

93. Murayama G, Chiba A, Kuga T, Makiyama A, Yamaji K, Tamura N, et al. Inhibition of mTOR Suppresses IFNalpha Production and the STING Pathway in Monocytes From Systemic Lupus Erythematosus Patients. Rheumatol (Oxford England) (2020) 59(10):2992-3002. doi: 10.1093/ rheumatology/keaa060

94. Sharma S, Campbell AM, Chan J, Schattgen SA, Orlowski GM, Nayar R, et al. Suppression of Systemic Autoimmunity by the Innate Immune Adaptor STING. Proc Natl Acad Sci (2015) 112:E710-7. doi: 10.1073/ pnas. 1420217112

95. Konig N, Fiehn C, Wolf C, Schuster M, Cura Costa E, Tungler V, et al. Familial Chilblain Lupus Due to a Gain-of-Function Mutation in STING. Ann Rheumatic Dis (2017) 76:468-72. doi: 10.1136/annrheumdis-2016209841

96. Fiehn C. Familial Chilblain Lupus - What Can We Learn From Type I Interferonopathies? Curr Rheumatol Rep (2017) 19:61. doi: 10.1007/s11926017-0689-x

97. King TEJr., Pardo A, Selman M. Idiopathic Pulmonary Fibrosis. Lancet (2011) 378:1949-61. doi: 10.1016/S0140-6736(11)60052-4

98. Richeldi L, Collard HR, Jones MG. Idiopathic Pulmonary Fibrosis. Lancet (2017) 389:1941-52. doi: 10.1016/S0140-6736(17)30866-8

99. Martinez FJ, Collard HR, Pardo A, Raghu G, Richeldi L, Selman M, et al. Idiopathic Pulmonary Fibrosis. Nat Rev Dis Primers (2017) 3:17074. doi: 10.1038/nrdp.2017.74

100. Strieter RM, Mehrad B. New Mechanisms of Pulmonary Fibrosis. Chest (2009) 136:1364-70. doi: 10.1378/chest.09-0510
101. Savigny F, Schricke C, Lacerda-Queiroz N, Meda M, Nascimento M, HuotMarchand S, et al. Protective Role of the Nucleic Acid Sensor STING in Pulmonary Fibrosis. Front Immunol (2020) 11:588799. doi: 10.3389/ fimmu.2020.588799

102. Qiu H, Weng D, Chen T, Shen L, Chen SS, Wei YR, et al. Stimulator of Interferon Genes Deficiency in Acute Exacerbation of Idiopathic Pulmonary Fibrosis. Front Immunol (2017) 8:1756. doi: 10.3389/fimmu.2017.01756

103. Ryu C, Sun H, Gulati M, Herazo-Maya JD, Chen Y, Osafo-Addo A, et al. Extracellular Mitochondrial DNA Is Generated by Fibroblasts and Predicts Death in Idiopathic Pulmonary Fibrosis. Am J Respir Crit Care Med (2017) 196:1571-81. doi: 10.1164/rccm.201612-2480OC

104. Zhao Q, Manohar M, Wei Y, Pandol SJ, Habtezion A. STING Signalling Protects Against Chronic Pancreatitis by Modulating Th17 Response. Gut (2019) 68:1827-37. doi: 10.1136/gutjnl-2018-317098

105. Zhang Y, Chen W, Wang Y. STING Is an Essential Regulator of Heart Inflammation and Fibrosis in Mice With Pathological Cardiac Hypertrophy via Endoplasmic Reticulum (ER) Stress. Biomed Pharmacother $=$ Biomed Pharmacother (2020) 125:110022. doi: 10.1016/j.biopha.2020.110022

106. Iracheta-Vellve A, Petrasek J, Gyongyosi B, Satishchandran A, Lowe P, Kodys K, et al. Endoplasmic Reticulum Stress-Induced Hepatocellular Death Pathways Mediate Liver Injury and Fibrosis via Stimulator of Interferon Genes. J Biol Chem (2016) 291:26794-805. doi: 10.1074/jbc.M116.736991

107. Petrasek J, Iracheta-Vellve A, Csak T, Satishchandran A, Kodys K, KurtJones EA, et al. STING-IRF3 Pathway Links Endoplasmic Reticulum Stress With Hepatocyte Apoptosis in Early Alcoholic Liver Disease. Proc Natl Acad Sci USA (2013) 110:16544-9. doi: 10.1073/pnas.1308331110

108. Benmerzoug S, Rose S, Bounab B, Gosset D, Duneau L, Chenuet P, et al. STINGDependent Sensing of Self-DNA Drives Silica-Induced Lung Inflammation. Nat Commun (2018) 9:5226. doi: 10.1038/s41467-018-07425-1

109. Lumeng CN, Saltiel AR. Inflammatory Links Between Obesity and Metabolic Disease. J Clin Invest (2011) 121:2111-7. doi: 10.1172/JCI57132

110. Qiao JT, Cui C, Qing L, Wang LS, He TY, Yan F, et al. Activation of the STING-IRF3 Pathway Promotes Hepatocyte Inflammation, Apoptosis and Induces Metabolic Disorders in Nonalcoholic Fatty Liver Disease. Metab: Clin Exp (2018) 81:13-24. doi: 10.1016/j.metabol.2017.09.010

111. Mao Y, Luo W, Zhang L, Wu W, Yuan L, Xu H, et al. STING-IRF3 Triggers Endothelial Inflammation in Response to Free Fatty Acid-Induced Mitochondrial Damage in Diet-Induced Obesity. Arterioscler Thromb Vasc Biol (2017) 37:920-9. doi: 10.1161/ATVBAHA.117.309017

112. Luo X, Li H, Ma L, Zhou J, Guo X, Woo SL, et al. Expression of STING Is Increased in Liver Tissues From Patients With NAFLD and Promotes Macrophage-Mediated Hepatic Inflammation and Fibrosis in Mice. Gastroenterology (2018) 155:1971-1984.e1974. doi: 10.1053/j.gastro.2018. 09.010

113. King KR, Aguirre AD, Ye YX, Sun Y, Roh JD, Ng RP Jr, et al. IRF3 and Type I Interferons Fuel a Fatal Response to Myocardial Infarction. Nat Med (2017) 23:1481-7. doi: 10.1038/nm.4428

114. Cao DJ, Schiattarella GG, Villalobos E, Jiang N, May HI, Li T, et al. Cytosolic DNA Sensing Promotes Macrophage Transformation and Governs Myocardial Ischemic Injury. Circulation (2018) 137:2613-34. doi: 10.1161/ CIRCULATIONAHA.117.031046

115. Lei Z, Deng M, Yi Z, Sun Q, Shapiro RA, Xu H, et al. cGAS-Mediated Autophagy Protects the Liver From Ischemia-Reperfusion Injury Independently of STING. Am J Physiol Gastrointest Liver Physiol (2018) 314:G655-67. doi: 10.1152/ajpgi.00326.2017

116. Rabe KF, Watz H. Chronic Obstructive Pulmonary Disease. Lancet (2017) 389:1931-40. doi: 10.1016/S0140-6736(17)31222-9

117. Nascimento M, Gombault A, Lacerda-Queiroz N, Panek C, Savigny F, Sbeity $M$, et al. Self-DNA Release and STING-Dependent Sensing Drives Inflammation to Cigarette Smoke in Mice. Sci Rep (2019) 9:14848. doi: 10.1038/s41598-019-51427-y

118. King PT, Sharma R, O’Sullivan KM, Callaghan J, Dousha L, Thomas B, et al. Deoxyribonuclease 1 Reduces Pathogenic Effects of Cigarette Smoke Exposure in the Lung. Sci Rep (2017) 7:12128. doi: 10.1038/s41598-01712474-5

119. Qin H, Huang G, Gao F, Huang B, Wang D, Hu X, et al. Diminished Stimulator of Interferon Genes Production With Cigarette Smoke-Exposure Contributes to Weakened Anti-Adenovirus Vectors Response and 
Destruction of Lung in Chronic Obstructive Pulmonary Disease Model. Exp Cell Res (2019) 382(1):111545. doi: 10.1016/j.yexcr.2019.111545

120. García-Valero J, Olloquequi J, Montes JF, Rodríguez E, Martín-Satué M, Texidó L, et al. Correction: Deficient Pulmonary IFN- $\beta$ Expression in COPD Patients. PloS One (2019) 14:e0219349. doi: 10.1371/journal.pone.0219349

121. Donnelly CR, Jiang C, Andriessen AS, Wang K, Wang Z, Ding H, et al. STING Controls Nociception via Type I Interferon Signalling in Sensory Neurons. Nature (2021) 591:275-80. doi: 10.1038/s41586-020-03151-1

122. Yu CH, Davidson S, Harapas CR, Hilton JB, Mlodzianoski MJ, Laohamonthonkul P, et al. TDP-43 Triggers Mitochondrial DNA Release via mPTP to Activate cGAS/STING in ALS. Cell (2020) 183:636-49.e618. doi: 10.1016/j.cell.2020.09.020

123. Sliter DA, Martinez J, Hao L, Chen X, Sun N, Fischer TD, et al. Parkin and PINK1 Mitigate STING-Induced Inflammation. Nature (2018) 561:258-62. doi: 10.1038/s41586-018-0448-9

124. Kwon OC, Song JJ, Yang Y, Kim SH, Kim JY, Seok MJ, et al. SGK1 Inhibition in Glia Ameliorates Pathologies and Symptoms in Parkinson Disease Animal Models. EMBO Mol Med (2021) 13:e13076. doi: 10.15252/emmm.202013076

125. Zhao M, Wang B, Zhang C, Su Z, Guo B, Zhao Y, et al. The DJ1-Nrf2-STING Axis Mediates the Neuroprotective Effects of Withaferin A in Parkinson's Disease. Cell Death Differ (2021) 28:2517-35. doi: 10.1038/s41418-021-00767-2

126. Jauhari A, Baranov SV, Suofu Y, Kim J, Singh T, Yablonska S, et al. Melatonin Inhibits Cytosolic Mitochondrial DNA-Induced Neuroinflammatory Signaling in Accelerated Aging and Neurodegeneration. J Clin Invest (2020) 130:3124-36. doi: $10.1172 /$ JCI1 35026

127. Sharma M, Rajendrarao S, Shahani N, Ramírez-Jarquín UN, Subramaniam S. Cyclic GMP-AMP Synthase Promotes the Inflammatory and Autophagy Responses in Huntington Disease. Proc Natl Acad Sci USA (2020) 117:15989-99. doi: 10.1073/pnas.2002144117

128. Gamdzyk M, Doycheva DM, Araujo C, Ocak U, Luo Y, Tang J, et al. cGAS/ STING Pathway Activation Contributes to Delayed Neurodegeneration in Neonatal Hypoxia-Ischemia Rat Model: Possible Involvement of LINE-1. Mol Neurobiol (2020) 57:2600-19. doi: 10.1007/s12035-020-01904-7

129. Bakhoum SF, Cantley LC. The Multifaceted Role of Chromosomal Instability in Cancer and Its Microenvironment. Cell (2018) 174:1347-60. doi: 10.1016/ j.cell.2018.08.027

130. Andzinski L, Spanier J, Kasnitz N, Kroger A, Jin L, Brinkmann MM, et al. Growing Tumors Induce a Local STING Dependent Type I IFN Response in Dendritic Cells. Int J Cancer (2016) 139:1350-7. doi: 10.1002/ijc.30159

131. Ohkuri T, Ghosh A, Kosaka A, Zhu J, Ikeura M, David M, et al. STING Contributes to Antiglioma Immunity via Triggering Type I IFN Signals in the Tumor Microenvironment. Cancer Immunol Res (2014) 2:1199-208. doi: 10.1158/2326-6066.CIR-14-0099

132. Kitajima S, Ivanova E, Guo S, Yoshida R, Campisi M, Sundararaman SK, et al. Suppression of STING Associated With LKB1 Loss in KRAS-Driven Lung Cancer. Cancer Discov (2019) 9:34-45. doi: 10.1158/2159-8290.CD-18-0689

133. Ho SS, Zhang WY, Tan NY, Khatoo M, Suter MA, Tripathi S, et al. The DNA Structure-Specific Endonuclease MUS81 Mediates DNA Sensor STINGDependent Host Rejection of Prostate Cancer Cells. Immunity (2016) 44:1177-89. doi: 10.1016/j.immuni.2016.04.010

134. Wu J, Dobbs N, Yang K, Yan N. Interferon-Independent Activities of Mammalian STING Mediate Antiviral Response and Tumor Immune Evasion. Immunity (2020) 53:115-26.e115. doi: 10.1016/j.immuni.2020.06.009

135. Chen Q, Boire A, Jin X, Valiente M, Er EE, Lopez-Soto A, et al. CarcinomaAstrocyte Gap Junctions Promote Brain Metastasis by cGAMP Transfer. Nature (2016) 533:493-8. doi: 10.1038/nature18268

136. Liu H, Zhang H, Wu X, Ma D, Wu J, Wang L, et al. Nuclear cGAS Suppresses DNA Repair and Promotes Tumorigenesis. Nature (2018) 563:131-6. doi: 10.1038/s41586-018-0629-6

137. Zhou Y, Fei M, Zhang G, Liang WC, Lin W, Wu Y, et al. Blockade of the Phagocytic Receptor MerTK on Tumor-Associated Macrophages Enhances P2X7R-Dependent STING Activation by Tumor-Derived cGAMP. Immunity (2020) 52:357-73.e359. doi: 10.1016/j.immuni. 2020.01.014

138. Corrales L, Glickman LH, McWhirter SM, Kanne DB, Sivick KE, Katibah GE, et al. Direct Activation of STING in the Tumor Microenvironment Leads to Potent and Systemic Tumor Regression and Immunity. Cell Rep (2015) 11:1018-30. doi: 10.1016/j.celrep.2015.04.031
139. Sivick KE, Desbien AL, Glickman LH, Reiner GL, Corrales L, Surh NH, et al. Magnitude of Therapeutic STING Activation Determines CD8(+) T CellMediated Anti-Tumor Immunity. Cell Rep (2018) 25:3074-85.e3075. doi: 10.1016/j.celrep.2018.11.047

140. Curran E, Chen X, Corrales L, Kline DE, Dubensky TWJr., Duttagupta P, et al. STING Pathway Activation Stimulates Potent Immunity Against Acute Myeloid Leukemia. Cell Rep (2016) 15:2357-66. doi: 10.1016/j.celrep. 2016.05.023

141. Okazaki T, Chikuma S, Iwai Y, Fagarasan S, Honjo T. A Rheostat for Immune Responses: The Unique Properties of PD-1 and Their Advantages for Clinical Application. Nat Immunol (2013) 14:1212-8. doi: 10.1038/ni.2762

142. Leach DR, Krummel MF, Allison JP. Enhancement of Antitumor Immunity by CTLA-4 Blockade. Science (1996) 271:1734-6. doi: 10.1126/science.271.5256.1734

143. Rivera Vargas T, Apetoh L. Can Immunogenic Chemotherapies Relieve Cancer Cell Resistance to Immune Checkpoint Inhibitors? Front Immunol (2019) 10:1181. doi: 10.3389/fimmu.2019.01181

144. Puyo S, Montaudon D, Pourquier P. From Old Alkylating Agents to New Minor Groove Binders. Crit Rev Oncol/Hematol (2014) 89:43-61. doi: 10.1016/j.critrevonc.2013.07.006

145. Ghiringhelli F, Apetoh L, Tesniere A, Aymeric L, Ma Y, Ortiz C, et al. Activation of the NLRP3 Inflammasome in Dendritic Cells Induces IL-1 $\beta$ Dependent Adaptive Immunity Against Tumors. Nat Med (2009) 15:1170-8. doi: $10.1038 / \mathrm{nm} .2028$

146. Wu JJ, Zhao L, Hu HG, Li WH, Li YM. Agonists and Inhibitors of the STING Pathway: Potential Agents for Immunotherapy. Med Res Rev (2020) 40:1117-41. doi: 10.1002/med.21649

147. Vanpouille-Box C, Alard A, Aryankalayil MJ, Sarfraz Y, Diamond JM, Schneider RJ, et al. DNA Exonuclease Trexl Regulates RadiotherapyInduced Tumour Immunogenicity. Nat Commun (2017) 8:15618. doi: 10.1038/ncomms 15618

148. Fu J, Kanne DB, Leong M, Glickman LH, McWhirter SM, Lemmens E, et al. STING Agonist Formulated Cancer Vaccines can Cure Established Tumors Resistant to PD-1 Blockade. Sci Trans Med (2015) 7:283ra252. doi: 10.1126/ scitranslmed.aaa4306

149. Dikic I, Elazar Z. Mechanism and Medical Implications of Mammalian Autophagy. Nature Reviews. Mol Cell Biol (2018) 19:349-64. doi: 10.1038/ s41580-018-0003-4

150. Nassour J, Radford R, Correia A, Fuste JM, Schoell B, Jauch A, et al. Autophagic Cell Death Restricts Chromosomal Instability During Replicative Crisis. Nature (2019) 565:659-63. doi: 10.1038/s41586-019-0885-0

151. Prabakaran T, Bodda C, Krapp C, Zhang BC, Christensen MH, Sun C, et al. Attenuation of cGAS-STING Signaling Is Mediated by a P62/SQSTM1Dependent Autophagy Pathway Activated by TBK1. EMBO J (2018) 37: e97858. doi: 10.15252/embj.201797858

152. Liu Q, Wu J, Zhang X, Li X, Wu X, Zhao Y, et al. Circulating Mitochondrial DNA-Triggered Autophagy Dysfunction via STING Underlies SepsisRelated Acute Lung Injury. Cell Death Dis (2021) 12:673. doi: 10.1038/ s41419-021-03961-9

153. Yamazaki T, Kirchmair A, Sato A, Buqué A, Rybstein M, Petroni G, et al. Mitochondrial DNA Drives Abscopal Responses to Radiation That Are Inhibited by Autophagy. Nat Immunol (2020) 21:1160-71. doi: 10.1038/ s41590-020-0751-0

154. Rongvaux A, Jackson R, Harman CCD, Li T, West AP, de Zoete MR, et al. Apoptotic Caspases Prevent the Induction of Type I Interferons by Mitochondrial DNA. Cell (2014) 159:1563-77. doi: 10.1016/j.cell.2014.11.037

155. White MJ, McArthur K, Metcalf D, Lane RM, Cambier JC, Herold MJ, et al. Apoptotic Caspases Suppress mtDNA-Induced STING-Mediated Type I IFN Production. Cell (2014) 159:1549-62. doi: 10.1016/j.cell.2014.11.036

156. Ning X, Wang Y, Jing M, Sha M, Lv M, Gao P, et al. Apoptotic Caspases Suppress Type I Interferon Production via the Cleavage of cGAS, MAVS, and IRF3. Mol Cell (2019) 74:19-31.e17. doi: 10.1016/j.molcel.2019.02.013

157. Zierhut C, Yamaguchi N, Paredes M, Luo JD, Carroll T, Funabiki H. The Cytoplasmic DNA Sensor cGAS Promotes Mitotic Cell Death. Cell (2019) 178:302-15.e323. doi: 10.1016/j.cell.2019.05.035

158. Sze A, Belgnaoui SM, Olagnier D, Lin R, Hiscott J, van Grevenynghe J. Host Restriction Factor SAMHD1 Limits Human T Cell Leukemia Virus Type 1 Infection of Monocytes via STING-Mediated Apoptosis. Cell Host Microbe (2013) 14:422-34. doi: 10.1016/j.chom.2013.09.009 
159. Aits S, Jäättelä M. Lysosomal Cell Death at a Glance. J Cell Sci (2013) 126:1905-12. doi: 10.1242/jcs.091181

160. Gonugunta VK, Sakai T, Pokatayev V, Yang K, Wu J, Dobbs N, et al. Trafficking-Mediated STING Degradation Requires Sorting to Acidified Endolysosomes and Can Be Targeted to Enhance Anti-Tumor Response. Cell Rep (2017) 21:3234-42. doi: 10.1016/j.celrep.2017.11.061

161. Sarhan J, Liu BC, Muendlein HI, Weindel CG, Smirnova I, Tang AY, et al. Constitutive Interferon Signaling Maintains Critical Threshold of MLKL Expression to License Necroptosis. Cell Death Differ (2019) 26:332-47. doi: 10.1038/s41418-018-0122-7

162. Bakhoum SF, Ngo B, Laughney AM, Cavallo JA, Murphy CJ, Ly P, et al. Chromosomal Instability Drives Metastasis Through a Cytosolic DNA Response. Nature (2018) 553:467-72. doi: 10.1038/nature25432

163. Yang H, Wang H, Ren J, Chen Q, Chen ZJ. cGAS Is Essential for Cellular Senescence. Proc Natl Acad Sci USA (2017) 114:E4612-20. doi: 10.1073/ pnas. 1705499114

164. Gluck S, Guey B, Gulen MF, Wolter K, Kang TW, Schmacke NA, et al. Innate Immune Sensing of Cytosolic Chromatin Fragments Through cGAS Promotes Senescence. Nat Cell Biol (2017) 19:1061-70. doi: 10.1038/ncb3586

165. Dou Z, Ghosh K, Vizioli MG, Zhu J, Sen P, Wangensteen KJ, et al. Cytoplasmic Chromatin Triggers Inflammation in Senescence and Cancer. Nature (2017) 550:402-6. doi: 10.1038/nature24050

166. Kreienkamp R, Graziano S, Coll-Bonfill N, Bedia-Diaz G, Cybulla E, Vindigni A, et al. A Cell-Intrinsic Interferon-Like Response Links Replication Stress to Cellular Aging Caused by Progerin. Cell Rep (2018) 22:2006-15. doi: 10.1016/j.celrep.2018.01.090

167. Swanson KV, Junkins RD, Kurkjian CJ, Holley-Guthrie E, Pendse AA, El Morabiti R, et al. A Noncanonical Function of cGAMP in Inflammasome Priming and Activation. J Exp Med (2017) 214:3611-26. doi: 10.1084/jem.20171749

168. Wang W, Hu D, Wu C, Feng Y, Li A, Liu W, et al. STING Promotes NLRP3 Localization in ER and Facilitates NLRP3 Deubiquitination to Activate the Inflammasome Upon HSV-1 Infection. PloS Pathog (2020) 16:e1008335. doi: 10.1371/journal.ppat.1008335

169. Aarreberg LD, Esser-Nobis K, Driscoll C, Shuvarikov A, Roby JA, Gale M Jr. Interleukin-1beta Induces mtDNA Release to Activate Innate Immune Signaling via cGAS-STING. Mol Cell (2019) 74:801-15.e806. doi: 10.1016/ j.molcel.2019.02.038

170. Kerur N, Fukuda S, Banerjee D, Kim Y, Fu D, Apicella I, et al. cGAS Drives Noncanonical-Inflammasome Activation in Age-Related Macular Degeneration. Nat Med (2018) 24:50-61. doi: 10.1038/nm.4450
171. Li M, Ferretti M, Ying B, Descamps H, Lee E, Dittmar M, et al. Pharmacological Activation of STING Blocks SARS-CoV-2 Infection. Sci Immunol (2021) 6:eabi9007. doi: 10.1126/sciimmunol.abi9007

172. Humphries F, Shmuel-Galia L, Jiang Z, Wilson R, Landis P, Ng SL, et al. A Diamidobenzimidazole STING Agonist Protects Against SARSCoV-2 Infection. Sci Immunol (2021) 6:eabi9002. doi: 10.1126/sciimmunol. abi9002

173. Gutjahr A, Papagno L, Nicoli F, Kanuma T, Kuse N, Cabral-Piccin MP, et al. The STING Ligand cGAMP Potentiates the Efficacy of VaccineInduced CD8+ T Cells. JCI Insight (2019) 4:e125107. doi: 10.1172/ jci.insight. 125107

174. Madhun AS, Haaheim LR, Nilsen MV, Cox RJ. Intramuscular Matrix-MAdjuvanted Virosomal H5N1 Vaccine Induces High Frequencies of Multifunctional Th1 CD4+ Cells and Strong Antibody Responses in Mice. Vaccine (2009) 27:7367-76. doi: 10.1016/j.vaccine.2009.09.044

175. Hu DL, Narita K, Hyodo M, Hayakawa Y, Nakane A, Karaolis DK. C-DiGMP as a Vaccine Adjuvant Enhances Protection Against Systemic Methicillin-Resistant Staphylococcus Aureus (MRSA) Infection. Vaccine (2009) 27:4867-73. doi: 10.1016/j.vaccine.2009.04.053

176. Ebensen T, Libanova R, Schulze K, Yevsa T, Morr M, Guzman CA. Bis(3',5')-Cyclic Dimeric Adenosine Monophosphate: Strong Th1/Th2/Th17 Promoting Mucosal Adjuvant. Vaccine (2011) 29:5210-20. doi: 10.1016/ j.vaccine.2011.05.026

Conflict of Interest: The authors declare that the research was conducted in the absence of any commercial or financial relationships that could be construed as a potential conflict of interest.

Publisher's Note: All claims expressed in this article are solely those of the authors and do not necessarily represent those of their affiliated organizations, or those of the publisher, the editors and the reviewers. Any product that may be evaluated in this article, or claim that may be made by its manufacturer, is not guaranteed or endorsed by the publisher.

Copyright (C) 2021 Couillin and Riteau. This is an open-access article distributed under the terms of the Creative Commons Attribution License (CC BY). The use, distribution or reproduction in other forums is permitted, provided the original author(s) and the copyright owner(s) are credited and that the original publication in this journal is cited, in accordance with accepted academic practice. No use, distribution or reproduction is permitted which does not comply with these terms. 